\title{
An evolutionary account of impairment of self in cognitive disorders
}

Antonio Benítez-Burraco ${ }^{1}$, Ines Adornetti ${ }^{2}$, Francesco Ferretti ${ }^{2}$, and Ljiljana Progovac ${ }^{3}$

1. Department of Spanish, Linguistics, and Theory of Literature (Linguistics), Faculty of Philology, University of Seville, Seville, Spain

2. Cosmic Lab, Department of Philosophy, Communication and Performing Arts. Roma Tre University, Rome, Italy

3. Linguistics Program, Department of English, Wayne State University, Detroit, USA 


\begin{abstract}
Recent research has proposed that certain aspects of psychosis, as experienced in e.g. schizophrenia $(\mathrm{SCH})$, but also aspects of other cognitive conditions, such as autism spectrum disorders (ASD) and synesthesia, can be related to a shattered sense of the notion of self. In this paper, our goal is to show that altered processing of the self can be attributed to an abnormal functioning of cortico-striatal brain networks supporting, among other, one key human distinctive cognitive ability, namely, cross-modality, which plays multiple roles in human cognition and language. Specifically, our hypothesis is that this cognitive mechanism sheds light both on some basic aspects of the minimal self and on some aspects related to higher forms of the self, such as the narrative self. We further link the atypical functioning in these conditions to some recent evolutionary changes in our species, specifically, an atypical presentation of human self-domestication (HSD) features. In doing so, we also lean on previous work concerning the link between cognitive disorders and language evolution under the effects of HSD. We further show that this approach can unify both linguistic and non-linguistic symptoms of these conditions through deficits in the notion of self. Our considerations provide further support for the hypothesis that $\mathrm{SCH}$ and ASD are diametrically opposed cognitive conditions, as well for the hypothesis that their etiology is associated with recent human evolution, leading to a deeper understanding of the causes and symptoms of these disorders, and providing new cues, which can be used for an earlier and more accurate diagnostics.
\end{abstract}

Key words: cognitive disorders; notion of self; human self-domestication; aggression; crossmodality 


\section{Introduction}

Schizophrenia (SCH) and autism spectrum disorders (ASD) are prevalent neurodevelopmental conditions often resulting in several highly distinctive cognitive and social characteristics, including deficits in language structure and use (Bailey et al. 1996, Tager-Flusberg et al. 2005, van Os and Kapur 2009, Stephane et al. 2014). Both conditions emerge from a complex interaction among genetic alterations, epigenetic changes, and environmental factors, resulting in an atypical development and wiring of selected brain pathways during growth, which in turn impacts upon diverse cognitive functions and ultimately results in their distinctive neurocognitive and behavioral profiles (Li et al. 2009, Stefanatos and Baron, 2011, Bakhshi and Chance 2015, Cannon 2015). Crespi and Badcock (2008) pointed out that SCH and ASD exhibit quite opposite features, from neurodevelopment to brain structure and function to cognitive abilities to behavior. Specifically, they noted that the two disorders can be regarded as mirror conditions for traits related to our social brain, including social cognition, gaze, and agency (hyperdeveloped in SCH and underdeveloped in ASD). Ultimately, they hypothesized that these differences may result from opposite patterns of abnormal genomic imprinting. Ongoing research on the etiology of SCH and ASD suggests that an altered notion of the self could be a key factor accounting for many distinctive features of these two conditions and that with respect to this notion of self, $\mathrm{SCH}$ and ASD can be regarded as mirror conditions too. Accordingly, ASD seems to correlate with an inflated sense of self (e.g., Frith and Happé 1999; Lombardo and Baron-Cohen, 2010), whereas a deflated, diminished sense of self can be posited for SCH (e.g., Henriksen and Nordgaard, 2014; Lysaker and Lysaker, 2010). Altered notion of self is also found in other conditions of interest for our proposal, particularly, some forms of synesthesia (e.g., Banissy and Ward, 2016; Cioffi et al., 2016). All three conditions present with altered patterns of cross-modality, which will be a central concern for us. We consider 
cross-modality to be one key feature of the human cognitive phenotype, the feature that enables one to transcend the boundaries of core cognitive systems (in the sense of Spelke, 2000, 2003; Spelke and Kinzler, 2007), thus allowing us, among other things, (i) to merge concepts and create new ones, (ii) to chunk syntactic pieces and form more complex syntactic structures, and (iii) to put into relation different domains, as attested in figurative uses of language.

In this paper, we will present evidence supporting the view that altered sense of self in conditions like $\mathrm{SCH}, \mathrm{ASD}$, or synesthesia can be linked to an atypical presentation of specific innovations in the evolution of human cognition, particularly, cross-modality, and, that it might result, partly, from an altered manifestation of features of human self-domestication (HSD). According to the HSD hypothesis, several key aspects of the human distinctive phenotype are the outcome of an evolutionary process similar to animal domestication (Hare, 2017). Under this view, different factors (e.g. the advent of co-parenting, the rise of community living, changes in our foraging ecology, and/or the deterioration of the human environment during the Last Glaciation) promoted selection in humans against reactive aggression and toward prosocial behavior, this resulting in physical, behavioral, and even cognitive changes that enhanced our social cognition, cooperation and social networks, and that paved the way toward our advanced technology and sophisticated culture (see Hare and Woods, 2020 for details). Because domestication results in more complex communicative signals in some animal species, particularly, songbirds, HSD has been claimed to have favored the emergence of many structural features of modern languages through a cultural mechanism (Thomas and Kirby, 2018; Benítez-Burraco and Progovac, 2020), but also of modern uses of language, that is, modern pragmatics (Benítez-Burraco et al., 2021) (for a gene-culture feedback loop in this respect, see Benítez-Burraco and Progovac, 2020, 2021). Interestingly, in line with the view that SCH and ASD are diametrically opposed conditions of the brain, these two conditions lie 
as well on the opposite poles of the HSD spectrum, with $\mathrm{SCH}$ showing some exaggerated features of HSD (Benítez-Burraco et al. 2017), and ASD showing certain attenuated features of HSD (Benítez-Burraco et al. 2016).

As we will show, the mechanism that links an altered presentation of HSD features in these conditions to an altered sense of self boils down to the management of aggression and its impact on cross-modality, which is at the core of the HSD hypothesis, and ultimately, to the inhibition/disinhibition in selected brain circuits. In Benítez-Burraco and Progovac (2021), we proposed that during human evolution, an enhanced connectivity between cortico-striatal networks emerged, firstly aimed at curtailing reactive physical aggression, but later aimed at accommodating simple grammars with metaphorical language, which relies heavily on the mechanism of cross-modality. Both processes (suppression of reactive aggression and crossmodality) clearly implicate cortico-striatal networks, and tend to cluster together in cognitive disorders. More specifically, our view is that both enhanced cross-modality and (the suppression of) reactive aggression, including verbal aggression, rely on a precise degree of (dis)inhibition of connectivity in the cortico-striatal brain circuits, the same circuits that are also essential for the processing of grammar, and language more generally. This entails that improved cross-modality, as observed in present-day humans, was (i) partly a result, or a sideeffect, of the HSD processes that initially favored specifically the dense connectivity in this network, enabling better control of reactive aggression by the higher, cortical structures of the brain, and (ii) partly a result of the cultural emergence of simple forms of language/grammar, relying heavily on metaphorical extension, which in turn contributed further to the connectivity of these brain networks, and to the reduction in reactive aggression. 
We find these considerations relevant for the etiology of SCH and ASD, as both conditions show altered management of aggression and altered processing of metaphorical (figurative) language. Hence, higher levels of reactive aggression are exhibited in ASD, in comparison to both typical and SCH populations (Hill et al. 2014; Fitzpatrick et al. 2016). With regards to metaphorical language, ASD often exhibits difficulties in establishing connections between two elements of a compound which rely on stretching the meaning (e.g. Riches et al., 2012; Kambanaros et al., 2019), as well as in understanding abstract concepts and metaphors more generally (Dodd, 2005: 47; Jordan, 2010). People with SCH can also be significantly impaired in the comprehension of novel metaphors (Rapp et al., 2018), as well as the comprehension of implicit information and humor (Pawełczyk et al., 2018). Nonetheless, SCH individuals exhibiting a mild, nonclinical manifestation of psychotic-affective conditions in fact show relative strengths, e.g. when interpreting metaphors, emotions, humor, and irony (Crespi, 2008: 238). In addition, relatives of people with $\mathrm{SCH}$ seem to have an advantage in artistic expression and originality (Fink et al., 2014). It is also of note that SCH presents with lower levels of reactive aggression relative to $\mathrm{ASD}$, but higher levels of proactive (i.e. premeditated) aggression (Bo et al. 2013). In other words, while both conditions, ASD and SZ, show deviation from the typical population, when compared with SZ, ASD shows markedly higher reactive aggression. Overall, this constitutes some evidence for ASD and SCH presenting with diametrically opposed symptoms in the domains of aggression management and figurative language, but also for milder or in-between conditions showing some adaptive advantages. ${ }^{1}$

Building on our previous work (specifically, Benítez-Burraco and Progovac, 2021), we contend that these opposite symptoms (in fact, opposite poles of a continuum) can be ascribed to

\footnotetext{
${ }^{1}$ In this respect, ASD shows an aptitude for rule-based systems and for hyper-systemizing (e.g. Baron-Cohen, 2009; Ward et al., 2017), which also contrasts with SCH.
} 
atypical inhibition (ASD) vs. disinhibition $(\mathrm{SCH})$ of global connectivity of the brain, more specifically connectivity in selected cortico-striatal brain networks, which, as noted, are involved in the control of reactive aggression, but also in cross-modality. Accordingly, it has been reported that, more generally, individuals with ASD differ from neurotypical subjects by being biased towards local, at the expense of global, conceptual processing, leading to difficulties in generalizing information, i.e. to a weakened drive to detect meaning by looking at the "big picture" (Happé and Frith, 2006). These features can be ascribed to reduced crossmodality, a result of inhibited global connectivity (Watanabe and Rees, 2016; Van Leeuwen et al., 2019). At the same time, individuals on the ASD spectrum often show increased local connectivity. As discussed below, this characterization of ASD can shed light, specifically, on the nature of the altered sense of self found in people on the spectrum, but also on the lack of global coherence in their narratives. By contrast, $\mathrm{SCH}$ seems to involve a profound failure of inhibition of global connectivity. In particular, Silbersweig and colleagues (1995) ascribe SCH hallucinations in both auditory and visual modalities to the abnormal disinhibition of corticalsubcortical circuits, which, as noted, are also involved in the management of aggression (see also Sterzer et al., 2018, Van Leeuwen et al., 2020, for alternative views of hallucinations in $\mathrm{SCH})$.

Interestingly, synesthesia can be characterized as exhibiting a combination of both increased local connectivity between sensory brain regions and enhanced global connectivity (Hubbard, 2007; Hubbard and Ramachandran, 2005). Synesthesia is not typically considered a disorder, but a condition in which stimulation of one sensory or cognitive pathway leads to automatic experiences in another sensory or cognitive pathway (Cytowic, 2002; Cytowic and Eagleman, 2009). According to Grossenbacher and Lovelace (2001), synesthesia is a result of disinhibited cortical sensory feedback (see also Cytowic, 1993, who emphasizes limbic mediation and 
cortical depression as relevant for synesthesia). One proposed explanation for this hyperconnectivity in synesthesia invokes a failure of adequate pruning of exuberant brain connections both locally and globally, the pruning that typically takes place in ontogeny (e.g. Maurer 1993; Baron-Cohen et al. 1993; Ramachandran and Hubbard, 2001; Mauer and Mondloch, 2006; Ward, 2013). Significantly, ASD has been characterized as a condition resulting from over-pruning of selected brain circuits, i.e. from aggressive synaptic pruning during childhood (Thomas et al., 2016). Interestingly, a key etiological factor of SCH seems to be an aberrant synaptic pruning in selected brain areas, particularly, the prefrontal cortex during adolescence (Woo, 2014).

These differences in local vs. global connectivity, and ultimately in excitatory vs. inhibitory synapses, apparently explain both the shared features and the differences between ASD, SCH, and synesthesia, for example why both ASD and synesthesia are advantageous for the attention to detail (correlated with enhanced local connectivity), whereas only synesthesia, as well as mild cases of $\mathrm{SCH}$, seem to also show advantages in creativity, metaphoricity, and imagination (correlated with enhanced global connectivity). In other words, both the vulnerabilities and the advantages exhibited by individuals with these conditions seem to result from an altered pattern of inhibition/disinhibition of brain connectivity, either locally, or globally, or both, with tradeoffs in systematicity and attention to detail, vs. creativity and imagination, the two sides acting as poles of otherwise continuous variability attested in humans. On this view, there is a dichotomy between perceiving the world as hyper-real (ASD-like) versus surreal (SCH-like), where synesthesia seems to fall somewhere midway. A similar pattern emerges, as noted, with regards to social functions, including aggression. In the next section, we rely on the findings and considerations outlined above to revisit the notion of self in ASD, SCH, and synesthesia. We provide new evidence in favor of the hypothesis that ASD and $\mathrm{SCH}$ represent two opposite 
poles of the social brain, specifically when it comes to the notion of self, this ultimately correlated with their opposite positions within the HSD spectrum. This construal can account for some of the peculiarities of the sense of self typically observed in these two conditions.

\section{The notion of self in SCH, ASD, and synesthesia}

SCH and ASD have long been described as disorders of the self (Bleuler, 1911/1950; Kanner, 1943; Asperger 1974). Bleuler (1911/1950) suggests that SCH is linked to an alteration in a person's basic sense of self - "the personality loses its unity" (p. 9) - stressing that persons with this disorder struggle to recognize themselves as subjects of their own experiences and agents of their own actions. In his famous early description of the children with autistic disturbances of affective contact, Kanner (1943) mentioned their difficulties in maintaining a constant self-concept and problems in adapting it to changing environment. A large body of research has linked some aspects of the impaired sense of self in $\mathrm{SCH}$ and ASD to the atypical functioning of social cognition observable in these conditions, including aberrant functioning of the Theory of Mind (ToM) system (e.g., Frith \& Happé 1999; Lysaker et al. 2011; Lyons and Fitzgerald 2013; Tordjman et al., 2019; Arnaud 2020). These aspects contribute to shape the dimension of the self that has been termed interpersonal self (Zahavi 2010): "It is the result of one's social interactions with other people, as well as one's ability to relate to other people. This dimension encompasses basic ways of differentiating oneself from others ... and more complex characteristics attributed to oneself, such as the way one appears to others, ... empathic or egocentric personality, openness to others and propensity to help" (Arnoud 2020, 3-4). Nonetheless, the concept of self is difficult to define. Different models have been proposed to account for its nature (e.g., Dennett 1991; Gallagher \& Shear 1999; Gallagher, 2000; Dehaene 2014; Zahavi 2014; Di Francesco, Marraffa, Paternoster, 2016). The difficulty of providing a definition of this concept arises from the fact that the self is a multifaceted entity 
entailing different functions, including (i) self-recognition (Meltzoff 1990; Lewis \& Ramsay 2004), (ii) body awareness (Mehling et al. 2009), (iii) sense of ownership (Gallagher, 2000; Tsakiris et al., 2007), (iv) sense of agency (Gallagher, 2000; Haggard, 2017), (v) self and other differentiation (Jeannerod, 2007), (vi) awareness of other minds (Frith 2002; Decety \& Chaminade, 2003), and (vii) awareness of being the same person across the time (Gallagher, 2000; Habermas \& Köber, 2014). Given the multiple functions constituting the self, we expect that its cognitive underpinnings are multiple too, going beyond ToM and including (but not limited to) social cognition (e.g., Uddin et al. 2007), executive functions (e.g., Hofmann et al 2012), and mental time travel (MTT), the cognitive system allowing to mentally project backward and forward in time (e.g., Quoidbach et al. 2008; Cosentino 2011; Adornetti \& Ferretti 2021).

Below, we provide a brief characterization of how three central dimensions of the self ((i) ownership and (ii) agency, section 2.1., and (iii) self-other differentiation, section 2.2.), as well as the underlying cognitive functions, manifest as altered in $\mathrm{SCH}, \mathrm{ASD}$, and, to some extent, synesthesia. In this paper, we focus on aspects that can be attributed to atypical patterns of brain connectivity and inhibition/disinhibition.

\subsection{Sense of ownership and sense of agency}

The sense of ownership and the sense of agency constitute what Gallagher and Zahavi (Gallagher, 2000; Zahavi, 2010; Gallagher and Zahavi, 2012; Zahavi, 2014) labelled minimal self, i.e., a self that is accessible to immediate self-awareness: "a consciousness of oneself as an immediate subject of experience, unextended in time" (Gallagher, 2000, p. 15). The sense of ownership refers to the feeling that one's body is one's own (i.e., the sense that it is my body that is moving), whereas the sense of agency refers to the experience of controlling one's own 
actions and, through them, the course of events in the outside environment (Haggard 2017). Along with other social-cognitive processes (i.e., joint attention, gaze monitoring, and the detection of intentional movements), it is considered to be an important developmental precursor of ToM (Abu-Akel, 2003, Decety and Chaminade, 2003). Russell (1996) proposed that an impairment in agency monitoring processes could impact upon the acquisition of ToM.

In this respect, $\mathrm{SCH}$ exhibits abnormalities both in the sense of ownership (e.g., Peled et al., 2000; Ferri et al., 2014; Gallese and Ferri 2014) and in the sense of agency (e.g., Frith et al., 2000; Garbarini et al., 2016). Atypical body ownership in SCH has been investigated through paradigms such as the Rubber Hand Illusion (Peled et al., 2000; Thakkar et al., 2011), which is an example of multimodal/multisensory integration, i.e., visuo-tactile integration, that depends on proprioceptive processing. Botvinick and Cohen (1998) found that neurotypical individuals who watch a rubber hand being stroked while one's own unseen hand is being stroked simultaneously, often feel a sense of ownership over the rubber hand, along with a shift in perceived position of the real hand. Thakkar and colleagues (2011) explored this phenomenon in individuals with $\mathrm{SCH}$ and found that they reported a stronger Rubber Hand Illusion than controls. This result supports the view that individuals with SCH exhibit alterations in the multisensory integration relating to bodily self-experience. Interestingly, vividness of the illusion was associated with elevated hallucinations (in line with other studies, e.g., Peled et al., 2003), but also with delusions of reference and delusions of control.

Often some of these symptoms, such as acoustic-verbal hallucinations and delusions of alien control along with thought insertion, are interpreted as involving problems with the sense of agency, which is also altered in SCH (Frith et al., 2000; Hur et al., 2014; Garbarini et al., 2016), leading to mistakes about the agency of various bodily movements (Frith \& Done 1989; 
Gallagher, 2000; Jeannerod, 2009; Renes et al 2013). Individuals who show these symptoms wrongly ascribe their experiences to other people with respect to agency, e.g., they state that someone else caused their actions. These represent attribution errors (under-attribution) and are the most frequently detected patterns in $\mathrm{SCH}$. The opposite pattern (over-attribution) may also be noted: i.e. the belief that they can control the thoughts and the behaviour of other people (aka megalomania) (Jeannerod, 2009, p. 530).

When it comes to ASD, contrasting results emerge. As for the sense of ownership, Paton and colleagues (2012) found that individuals with ASD experience the Rubber Hand Illusion to much the same degree as the control group. Cascio and colleagues (2012) investigated the phenomenon in children with ASD revealing that they were initially less susceptible to the illusion than the comparison group but showed the effects of the illusion after 6 minutes. Most studies investigating the sense of agency in ASD have reported no impairments in this process (e.g. Russell and Hill, 2001; David et al., 2008; Williams \& Happé, F., 2009). On the other hand, Russell and Jarrold (1999) report that children with ASD had difficulties in correctly deciding whether an action had been produced by themselves or by another agent. All in all, we can conclude that the sense of agency is more affected in SCH than it is in ASD.

As for synesthesia, research indicates that both the sense of ownership and the sense of agency are altered. For example, there is evidence that mirror-sensory synesthesia and responses to the Rubber Hand Illusion are related. In mirror-touch synesthesia (MTS), one of the most prevalent forms of synesthesia in which individuals feel tactile sensation on their own body by observing touch to other individuals (Blakemore et al., 2005; Banissy et al., 2009), the Rubber Hand Illusion occurs in the absence of synchronous tactile signals (Aimola et al., 2013). An investigation by Cioffi and colleagues (2016) found that the sense of agency is also affected in 
MTS. In their study the authors employed a vicarious agency paradigm: participants are placed in front of a mirror and an experimenter sits behind a curtain hidden from the participant's view. The participants listen to action instructions and then observe an action performed by the experimenter with his/her hands. The hand gesture performed by the experimenter could be congruent or incongruent with the instructions. For example, in the mismatch condition, after the instruction "make a waving gesture" the experimenter snaps their fingers. Cioffi and colleagues (2016) showed that individuals with MTS had a higher sense of agency over the movements in the congruent condition compared to non-synesthete controls, suggesting that "difficulties in self-other processing may be a fundamental disturbance in MTS" (Cioffi et al., 2016, p. 429). The results of this study are also relevant to shed light on the relationship between the sense of agency and the sense of ownership. In fact, Cioffi and colleagues (2016) also evaluated to what degree the participants felt that the arm belonged to him/her. In line with previous research attesting an amplified sense of ownership in MTS (Aimola et al., 2013; Maister et al., 2013), they found that in individuals with MTS there was a stronger feeling of ownership towards the experimenter's hands compared to controls in both match and mismatch conditions. According to Cioffi and colleagues (2016), this data suggests that in MTS "alterations in the sense of agency can be linked to more profound disturbances in the sense of ownership" (p., 426).

\subsection{Self-other differentiation}

Classical developmentalists, such as Baldwin (1902), Cooley (1902), Mead (1934), as well as modern developmentalists, such as Stern (1985) and Neisser (1988), have stressed the role of other persons in the development of the awareness of self. As Hobson (1990) maintained: "an individual requires a concept of other persons as subjects of experience if he is to acquire a developed concept of self (...) Awareness of persons - that is, awareness of other individuated 
centers of subjective orientations toward the world - is a precondition for self-reflection and self-consciousness, for indexical thought, and ultimately for an objective view of the mindindependent world" (Hobson, 1990, p. 155). The construction of reflexive forms of consciousness underlying the development of self seems to presuppose the recognition of others as persons. Within this theoretical framework, recognition of others as persons works as a mirror through which to look at oneself and, in this way, to gain one's own identity. This interpersonal foundation of the self relies on the process of self-other differentiation. Self-other differentiation can be achieved at spatial/bodily (Noel et al. 2017) and cognitive (Sowden \& Shah, 2014) levels. Accordingly, self/other differentiation involves both motor processes underpinning imitation and cognitive processes linked to mentalizing and reasoning about the other's beliefs and emotions (Eddy, 2018).

In this respect, $\mathrm{SCH}$ shows notable difficulties with self-other differentiation, at both body and cognitive levels. With respect to bodily/action differentiation, Liepelt and colleagues (2012) report that $\mathrm{SCH}$ individuals have a deficit in integrating one's own and other's actions. Noe and colleagues (2017) report that SCH individuals possess an extremely weak or variable bodily boundary between self and others (for the loss of the self-other boundary, see also Nelson et al., 2009; Thakkar et al., 2011; Michael and Park, 2016). For example, a diminished self-other boundary distinction in $\mathrm{SCH}$ is supported by a study by Delevoye-Turrell and colleagues (2011) on the peripersonal space (PPS) representation. In this study, individuals with SCH and controls were asked to judge the location of the boundary of PPS indicating when objects and people entered or exited their reaching space. Results revealed that individuals with SCH were significantly more variable in their judgments, and this higher variability correlated with the Positive and Negative Syndrome Scale (PANSS) score: the more severe the symptoms, the greater variability of judgments was observed. If atypically high levels of disinhibition in the 
cortico-striatal networks characterize $\mathrm{SCH}$, as we have proposed, then the shattered (notintegrated) sense of self in this condition can be seen as a failure to inhibit multisensory input in the construction and maintenance of self.

In contrast to SCH, Noe and colleagues (2017, p. 10) consider that ASD individuals possess a sharper self-other boundary than $\mathrm{SCH}$ individuals, suggesting a reverse pattern of the one attested in $\mathrm{SCH}$ : "SZ [i.e. $\mathrm{SCH}$ ] may represent a particular instance in which the distinction between self and others is exceptionally weak (i.e., too shallow of a PPS boundary), while ASD may represent a particular instance in which the distinction between self and other is exceptionally strong (i.e., too sharp of a PPS boundary)" Relating this to cross-modality, in contrast to $\mathrm{SCH}$, which is characterized by increased, uninhibited cross-modality, correlated with the self without a clear boundary, ASD is characterized by diminished, inhibited crossmodal connections, the inhibition that also extends to multisensory input necessary to fully experience and empathize with others. "In both of these cases the experience with others is likely to be impaired, which may then cascade into socio-communicative deficits and difficulties interacting with the physical world" (p. 10). The atypical degree of empathy and the lack of clearly bounded sense of self seems especially well-illustrated with the third condition we examine here, i.e. synesthesia, in particular because the essence of this condition has been attributed to enhanced cross-modality.

Mirror Touch Synesthesia (MTS) is a condition associated with atypical experiences with others (Banissy and Ward, 2013; de Guzman et al., 2016; Ioumpa et al., 2019). According to Banissy and Ward (2013), the amplified vicarious tactile experiences characteristic of this condition indeed depend on atypical self-other representations, namely on difficulties in the ability to differentiate representations of the self from others. This is particularly evident when 
individuals with MTS are administered the Enfacement Illusion test. In the Enfacement Illusion test, self-other recognition is evaluated before and after a stimulation session in which participants watch a video showing a series of images of morphed faces representing incremental changes from the participants' faces (self) to the faces of strangers (other). They are asked to indicate when they start/stop recognizing themselves in the video for the two directions of morphing: self to other and other to self. While looking at the video, subjects also receive tactile stimulation on the cheek and simultaneously watch a similar stimulation applied to the other in the video. Tsakiris (2008) found that in typical individuals synchronous tactile stimulation while watching another person's face being similarly touched produced a bias in recognizing one's own face: the images that the subjects had initially perceived as containing equal parts of self and other become more likely recognized as the self. Maister and colleagues (2013) developed an adapted version of this paradigm for MTS removing the tactile stimulation. The results of their study showed that subjects with MTS reported the same effect of enfacement illusion in the absence of the physical touch component, suggesting a blurring in the self-other distinction processes. As highlighted by the authors of the study, "these results suggest that observing touch on others not only elicits a conscious experience of touch in MTS, but also elicits a change in the mental representation of the self, blurring self-other boundaries. This is consistent with a multisensory account of the self, whereby integrated multisensory experiences maintain or update self-representations" (Maister et al., 2013, p. 802). If the representations of self depend on the precise integration of multisensory input, which in turn relies on multimodal connectivity of the brain, then it is expected that any disturbance in crossmodal connectivity may lead to an impaired sense of self. In particular, because of their enhanced cross-modality, it is expected that $\mathrm{SCH}$ and synesthesia will feature a more disintegrated, more shattered sense of self, with their propensity to reach to and experience the other, while ASD will show the opposite tendencies. 
The atypical multisensory processes that in SCH, ASD, and MTS affect self-other differentiation at spatial/bodily level also have consequences for the self-other differentiation occurring at the cognitive level and underlying some competences of social cognition. As previously mentioned, both SCH and ASD are characterized as disorders of social cognition, including of ToM. Such atypical functioning in social domains, including imitation and empathy, is also reported in MTS (de Guzman et al., 2016; Ioumpa et al., 2019). This atypical functioning of social cognition has indeed been related to atypical modulation of self-other representations not only in SCH and ASD (Cook and Bird, 2012; Ferri et al., 2012; Sowden and Shah 2014), but also in MTS (Kuang 2016). For example, deficits in ToM are typically disturbances in monitoring the intentions of others, specifically when these intentions are different from their own intentions. In this regard, it has been suggested that in SCH the phenomenon of paranoid delusions (e.g., delusions of persecutory control) can be attributed to a deficit in managing representations of self and others, namely a deficit in the ability to construct accurate mental representations of other individuals' intentions (Frith 1992; Allen et al. 2004; Harrington et al., 2005; Sowden \& Shah, 2014).

When it comes to ASD, in parallel with a sharper bodily separation between self and other, it can be also observed a cognitive differentiation as sharper than in the typical case, (as opposed to being too weak, as in the case of $\mathrm{SCH}$ ), in the sense that ASD individuals have a difficulty viewing themselves as embedded within social contexts. In this respect, Frith \& De Vignemont (2005) discuss the distinction between egocentrism and allocentrism in social cognition. For the egocentric stance, the other person is represented in relation to the self ("you"), while for the allocentric stance, there needs to exist a mental state of the other person represented as independent from the self ("he/she/they"). The egocentric perspective is a representation that 
comes from a direct self-knowledge; the allocentric stance is a representation of oneself as a person among others (p. 725). While neurotypical people can switch from one perspective to the other to readily achieve an integrated "sense of self," ASD people have difficulties with switching, and they tend to take an egocentric stance.

These considerations are not only consistent with treating ASD and SCH as diametrically opposed cognitive conditions, but more specifically, they are also consistent with ASD and $\mathrm{SCH}$ exhibiting mirror patterns with respect to cross-modality, as per our proposal, given that cross-modality is above all about crossing conceptual boundaries and merging conceptual domains. Research on self-other representations in synesthesia provides further support for this view. In fact, according to Santiesteban et al. (2015), "mirror-sensory synesthesia occurs when representations of others are not properly inhibited (while representations of the self are somewhat inhibited), whereas the opposite seems to be the case with deficits in Theory of Mind (ToM) and empathy found in individuals with ASD, which occur when representations of the self are not properly inhibited and representations of others are not enhanced enough.”

\section{From self to language: the use of pronouns as an example}

The cognitive systems underlying the construction of the self (both in neurotypical population and in $\mathrm{SCH}, \mathrm{ASD}$, and synesthesia) are intimately tied to language: the way we use language reflects important psychological factors relating to the way we represent our own self and the self of others. Accordingly, studying some aspects of language use by people with these conditions can offer a promising window to the underlying deficits in the domains of the notion of self and more generally, cross-modality. From a general point of view, in the light of what we have said so far about the altered sense of self in SCH, ASD, and synesthesia, we should expect to find in these conditions atypical language features that are characterizable in terms 
of the diametrical oppositions. In this section, we focus on the use of pronouns, the words that typically grammaticalize the self-other distinction (and the awareness of other persons), whereas in section 4, we consider the use of narratives, as one basic way of constructing one's identity by means of autobiographical stories.

Because of their noted role in grammaticalizing the participants in any conversational exchange, a widely shared opinion is that impairments in self-other distinctions, as found in $\mathrm{SCH}, \mathrm{ASD}$, and synesthesia, should be manifested in an atypical use of pronouns (e.g., Lombardo and Baron-Cohen, 2010; Stephane, Kuskowski et al., 2010). Children's ability to distinguish personal pronouns "I" and "you", or "mine" and "yours", emerges in the second year of life (e.g., Lewis \& Ramsay, 2004; Moyer et al., 2014), and is considered a manifestation of self-awareness. In fact, "The correct use of pronouns requires a representation of the listener's mind such that the speaker knows what the listener needs clarified (e.g. who exactly "she" represents in a sentence) and thus could reflect social cognitive skills" (Buck et al., 2015). This is clearly related to ToM, as previously introduced. From this perspective, the difficulty of successfully using personal pronouns in a conversational context seems to correlate with the difficulty of recognizing the reciprocal roles of speaker and listener in conversation. According to De Villiers and De Villiers (1974), the comprehension of deictic terms 'can only be understood by "non-egocentric" individuals who recognize the context of the relationship between the speaker and the addressee' (Hobson, 1990, p. 171). Similarly, Bruner (1975) highlights that 'children need to have grasped reciprocal roles in discourse before they can understand linguistic deixis' (Hobson, 1990, p. 171).

Taking all this into account, we can expect that ASD will show difficulties recognizing and maintaining the reciprocal roles in conversation, resulting in the tendency to avoid pronouns 
altogether (by using names instead), or to use them in atypical ways. Jordan (1989) analyzed the use of pronouns in a group of 11 children with ASD and reported that $72 \%$ of them used their own name for self-reference instead of the pronoun, while only $18 \%$ of language-matched controls did so (see also Sterponi et al. 2015, among others). As an example of such pronoun avoidance, consider having Jimmy saying "Jimmy likes apples" in lieu of "I like apples." This is certainly attested in early child speech, and there may be a prolonged period in which this is true of children on the ASD spectrum, and even adults with ASD (Lombardo et al., 2007). It has also been shown that children with ASD tend to reverse first person pronouns, using them to refer to other people. According to Kanner (1943, p. 244), in ASD “personal pronouns are repeated just as heard, with no change to suit the altered situation. The child, once told by his mother, 'Now I will give you your milk,' expresses the desire for milk in exactly the same words." Other investigations also reported an inappropriate use of second person pronouns. For example, it has been shown that children with ASD frequently use "You" to refer to themselves (Jordan 1989; Lee et al., 1994; Hobson et al, 2006; Shield et al. 2015). Similar atypical uses extend to third person pronouns. In a study on the use of pronouns in storytelling in people with ASD, Novogrodsky (2013) and Novogrodsky and Edelson (2016) found inappropriate use of the third person in storytelling tasks but not in (less onerous) retelling tasks. ${ }^{2}$ Similarly, Hobson and colleagues (2010) reported that participants with ASD were less likely to use third person pronouns. ${ }^{3}$

\footnotetext{
${ }^{2}$ Interestingly, this inappropriate use of third person pronouns was not limited to specific syntactic structure, which to the authors suggested "a cognitive deficit in monitoring the listener's mental model" (Novogrodsky and Edelson, 2016, p. 250).

${ }^{3}$ However, according to Finnegan et al. (2021), although pronominal reversal was once considered a defining characteristic of peculiar speech in ASD (APA, 1980), pronoun difficulties in individuals with ASD may be more nuanced than previously imagined; on this point, see also: Barokova and Tager-Flusberg (2019).
} 
Regarding $\mathrm{SCH}$, it has been suggested that the frequency of self-referential pronouns is a potential marker of psychosis (Fineberg et al. 2016; Palaniyappan 2021). In psychosis, formal thought disorder (that is, the inability to organize one's thoughts in a logical sequence with the aim of attaining a specific goal) manifests itself in disorganized speech resulting from atypical use of many types of words, including an excessive use of pronouns (Mackinley et al. 2021; Tang et al, 2021). Rochester and Martin (1979) reported that individuals with SCH frequently ineffectively explain to whom one is referring when using pronouns. One also finds a reduced use of first-person plural pronouns (Roy\& Chiat, 2013), and an increased use of first-person singular pronouns in SCH (Buck \& Penn, 2015; Tang et al. 2021), which the opposite tendency of what is found in ASD. Perhaps the preponderance of pronouns in $\mathrm{SCH}$ reflects their switching of perspective too fast and too often, relative to the typical population, while ASD avoids switching perspectives, and thus also avoids pronoun use. Taken on the whole, this suggests that ASD is characterized by the avoidance of pronouns, in comparison to the typical case, while $\mathrm{SCH}$ seems characterized by an excessive use of pronouns. These considerations again reveal an opposite disturbance in these two conditions, which can be related to the disturbance in the sense of self, and ultimately to the disturbance in cross-modality and brain connectivity.

When it comes to synesthesia, to the best of our knowledge, there are no studies explicitly investigating the use of pronouns in this condition. However, in the light of what we said in section 2, we can expect to find in MTS an increased use of pronouns, particularly first person pronouns. As mentioned above, in MTS we observe a blurring of the self-other differentiation affecting the empathic processes, which appear hyperactivated (e.g., Bolognini et al., 2013; Holle et al 2013). "Stronger empathy is expected because synesthetes experience on their own body any unpleasant sensation they observe in others: being more sensitive to 
other people's misfortunes, they would be more motivated to relieve others' suffering" (Ioumpa et al., 2019, p. 2). Accordingly, the reason why an excess of first person pronouns can be expected for MTS (increased empathy) would contrast with the reason why first person pronouns can be mis-used (or avoided) by people with ASD (increased egocentrism).

\section{The self and modes of narration}

Another fruitful way to analyze both the construction and alteration of the self in reference to language use in conditions like $\mathrm{SCH}, \mathrm{SZ}$, and synesthesia is to investigate the narrative dimension (e.g., Giddens, 1991; McAdams \& McLean, 2013; Allé et al., 2015; Altavilla et al., 2020; Adornetti and Ferretti 2021; Canali et al., 2021). This view is founded on the position that human beings construct their own identities by means of stories, e.g., by producing autobiographical narratives (Schechtman, 1996; McAdams, 2001; Habermas \& de Silveira,

2008). Paradigmatic of this perspective is Bruner's constructivist model of personal identity (e.g., Bruner, 2003, 2004). According to Bruner, autobiographical narratives support the integration of different aspects of personal experiences into a unitary representation. In this sense, these narratives might promote the construction of a coherently structured sense of self. In his words: "self-telling of life narratives achieves the power to structure perceptual experience, to organize memory, to segment and purpose-build the very 'events' of a life. In the end, we become the autobiographical narratives by which we 'tell about' our lives." (Bruner, 2004, p. 694). In the same vein, Dennett (1991) proposes that personal identity must be interpreted as a center of narrative gravity and Gallagher (2000) adheres to the view according to which human beings have a sense of a coherent and continuous self - i.e., a self that extends in time - because they have the ability to tell stories. 
From this it transpires that certain aspects of the atypical sense of self in SCH, ASD and synesthesia, can also be tied to (and manifest in) the disruptions of the narrative plan, which can best be illuminated by determining how the narratives generated by people with these conditions differ from those produced by neurotypical subjects. Before going into details, it is necessary to clarify what are the defining features of a narrative. At a general level, a narrative can be defined as a linguistic representation of temporally (e.g., Genette 1972) and causally (e.g., Trabasso and Sperry 1985) connected sequences of events, driven by the goals and motivations of one or more agents (Bruner 1997). Two main themes emerge from this definition: (i) the relationship between events in the flow of discourse (which boils down to the nature of the processes and the cognitive systems responsible for the causal and temporal connections between the events), and (ii) the nature of events and agency (i.e., how events and agency are represented in the mind). These are closely related themes that open the way for different strategies for analysis. We now focus on these two aspects.

\subsection{Relationship between events in the flow of discourse}

Concerning the relationship between events in the flow of discourse, of relevance are both the studies analyzing the cognitive systems (e.g., executive functions and MTT: Kerns and Berenbaum, H. 2002; Kerns 2007; Adornetti 2014; Ferretti et al., 2018; Marini et al., 2019) and those analyzing the brain structures (e.g., the hippocampus: Cohn-Sheehy et al., 2021; Milivojevic et al., 2016; Race et al., 2015), both of which are at the basis of the processing of the global coherence of the narrative plan. It is clear then that the systems responsible for these relationships important for discourse construction and interpretation have a cognitive foundation, and not merely a linguistic one. ${ }^{4}$ In this paper, we are adding the relevance of the

\footnotetext{
${ }^{4}$ Radwansky and Zacks write: "although causal information is conveyed in a text via the words used, causal relationship information appears to be primarily represented at the event model level, not the surface or text base levels (...). Causal relations serve as the backbone for understanding and remembering the narrative as a whole" (Radwansky and Zacks, 2014, p. 76).
} 
connectivity in the cortico-striatal brain networks, which are of direct relevance for crossmodality, as previously mentioned.

That $\mathrm{SCH}$ and ASD people have difficulties in managing the global coherence of a narrative is well documented (e.g., Andreasen 1979; Marini et al., 2008; Boudewyn et al., 2012; Stirling et al., 2014; Sah and Torng 2015; Boudewyn et al. 2017; Adornetti et al. 2020; Jolliffe and BaronCohen 2000). Specifically, it is demonstrated that some of the deficits in managing the global narrative plan affecting individuals with SCH and ASD can be linked to difficulties in coping with the causal connections between the constituent events of a story (Losh and Capps 2003; Diehl et al. 2006; Allé et al., 2015; Sah and Torng 2015; Allé et al., 2016a; Willits et al. 2018). Diehl and colleagues (2006) investigated story recall and narrative coherence in children with high functioning ASD and children with typical development. Their analysis revealed that the two groups produced stories that were comparable in length and syntactic complexity, but the narratives generated by the children with ASD were significantly less coherent, i.e., with fewer causal relationships evaluated in reference to a necessity test between events (an event A was considered to be necessary for an event B in that if event A has not occurred, event B would not have occurred). Analogous results have been found also where the causal relationships were evaluated in reference to explicit linguistic causal connections, such as 'because', 'that's why', 'so' (King et al., 2014). A similar pattern is also evident in the narratives produced by people with SCH. Willits and colleagues (2018) examined the semantic cohesion of personal narratives in SCH and found that they contained few connectives (e.g., because, and, although) to link words and phrases within sentences. According to the authors, "this means their audience was left without important cohesive links to connect ideas within a sentence and had to devote cognitive resources to make these connections" (p., 368). Difficulties of this kind in 
$\mathrm{SCH}$ can be observed also in narrative comprehension. Examining the modulation of the $\mathrm{N} 400^{5}$ in a discourse context, Ditman and Kuperberg (2007) revealed that SCH individuals have difficulties constructing coherent links across individual sentences to build up overall global context in discourse comprehension.

Some of the difficulties in the processing of the global narrative plan affecting individuals with $\mathrm{SCH}$ and ASD have also been referred to as problems in representing the temporal connections between events in the flow of discourse (Allé et al., 2015; Allé et al., 2016a, 2016b; Ferretti et al., 2018; Marini et al., 2019). At a general level, several lines of investigation suggest that a crucial role in this regard is played by the hippocampus (e.g., Duff et al. 2008; Race et al., 2015; Cohn-Sheehy et al. 2021), a brain structure embedded in the temporal lobe, which has been proposed to be one of main neural substrates of MTT (e.g., Maguire et al., 2016). In a study on amnesic individuals with medial temporal lobe damage, Race and colleagues (2015) found that hippocampus is involved in "the integration of linguistic elements into cohesive and coherent discourse units when constructing several different types of complex verbal narratives" (p., 279). The authors highlighted that these individuals had difficulties both in the production of fictional narratives and in the generation of personal stories about future and past events.

The findings by Race et al (2015) are particularly relevant in interpreting some peculiarities of the narrative deficits affecting individuals with SCH and ASD, given that reductions in the neural circuits typically associated with MTT (e.g., in the hippocampus) have been observed in these conditions (e.g., Dager et al., 2007; Zhou et al., 2008; Fornara et al., 2017; Cachia et

\footnotetext{
${ }^{5}$ The N400 is a component of the human scalp-recorded event-related brain potential (ERP) that reflects the semantic integration of words into a preceding context (word, sentence, or discourse) (e.g., Kutas and Hillyard, 1980; Kutas and Federmeier, 2011; Nieuwland and van Berkum, 2006).
} 
al., 2020; Banker et al., 2021). In line with these findings, Ferretti and colleagues (2018) showed that children with ASD with impaired MTT exhibited also impairments in generating coherent fictional stories. In this study, children with ASD were asked to generate past and future episodes of a narrative discourse and to complete a task aimed at assessing one of the subcomponents of MTT: their ability to project into a future scenario. Their performance was compared to that of a group of children with typical development. The results showed that children with ASD who were impaired in the ability to project into the future also performed significantly worse on the narrative production task: their fictional narratives contained more errors of global coherence (i.e., elements that were tangential or incongruent with the temporal storyline), more repetitions, and fewer causal links than the narratives of the children with typical development (see also Marini et al., 2019). These kinds of deficits also extend to the personal narratives of individuals with ASD (e.g., McCabe et al., 2013). Similarly, persons with SCH show difficulties in managing the temporal dimension of a narrative. It has been shown that when people with SCH are asked to narrate their life stories, they have difficulties to organize and locate events chronologically across the course of the narrative (Allè et al., 2015; Allé and colleagues 2016a, 2016b). Analyzing the temporal macrostructure of their life stories (i.e., elaboration of beginnings and endings, number of temporal indicators, number of anachronies in the narrative), Alle and colleagues (2016b) found that the global temporal coherence is significantly reduced in individuals with $\mathrm{SCH}$ and that "the lower temporal coherence in patients seems mainly associated with their tendency to spontaneously deviate from the chronological order of events without marking the deviation" (p. 26). As is the case with ASD, also in SCH the difficulties in managing the global temporal coherence seem to be related to anomalous functions of MTT. Research has indeed shown that individuals with SCH also have reduced ability to retrieve both specific events from their personal past and to imagine possible scenarios that might happen in their personal future (e.g., Cuervo-Lombard et al., 
2007; D'Argembeau et al., 2008; Raffard et al., 2013; Chen et al., 2016; Lyons et al., 2016; Yang et al., 2018; Malek et al. 2019).

From what has been said so far, it can be concluded that part of the difficulties in the construction of self in individuals with $\mathrm{SCH}$ and ASD can be linked to analogous difficulties in managing the narrative global coherence (the property that governs the causal and temporal relationship between events). Interestingly, when a narrative is analyzed in reference to the temporal and causal connections between the events, more similarities rather than differences between ASD and SCH seem to emerge. These similarities might be explained in reference to an anomalous activity of the hippocampus in ASD and $\mathrm{SCH}$ affecting the binding process between events. Indeed, it has been proposed that the hippocampus supports the integration of separated events into larger narratives (e.g., Cohn-Sheehy et al., 2021; MacKay, et al., 1998; 2007, Race et al., 2015). On the other hand, as shown in the next section, these conditions do exhibit opposite patterns when considering the second aspect involved in the definition of a narrative: the nature of event representations and agency.

\subsection{Event representation and agency}

Although the notion of event has a long philosophical tradition, our focus here is on event representation and agency (i.e., how they are represented in the mind). Following Sinha and Gärdenfors (2014), events often call into play situations "in which selves and other people figure as agents, performing actions directed to other agents and to objects” (2014, p. 1). More specifically, referring to the theory of conceptual spaces (Gärdenfors, 2000, 2014), the two authors describe such events "as built up from an agent, an action, a patient, and a result (...). The result of an event is modeled as a change vector representing the change of properties before and after the event" (Sinha and Gärdenfors, 2014, p. 5). According to Sinha and 
Gärdenfors, there is a very strong relationship between events and language (here referring to the propositional structure of utterances), given that "event structure, the combination of constituents encoding objects, actions, location, and motion, is the fundamental building block for sentence meaning and grammar" (Sinha and Gärdenfors, 2014, p. 1). Challenging this latter view, Radwansky and Zacks (2014) present a different perspective - The Event Horizon Model - according to which the representation of events is involved in discourse processing, rather than (or more than) in sentence processing. In their opinion, discourse processing is driven by generically cognitive rather than specifically linguistic systems: understanding discourses implies processes such as the ability to distinguish one event from another (event segmentation), also involved in the segmentation of the continuous flow of events in everyday life. Furthermore, the segmentation of events calls into play prospective forms of cognition. The anticipatory and predictive character of the segmentation of events plays a leading role in narrative competence, given that "one major function of event models in language comprehension is to enable predictions about what information is coming in a discourse" (Radwansky and Zacks, 2014, p. 59). Experimental investigations prove the importance of event segmentation in narrative comprehension. For example, Zacks and colleagues (2009) showed that, when reading a narrative, clauses relating to the representation of the transition points between one event and another (event boundaries) are read more slowly (i.e., required a greater effort on the part of the reader) than the clauses relating to the representation of an event. An increase in processing time coinciding with the segmentation of events during reading has also been observed in experiments with neuroimaging techniques (Speer et al., 2007).

When the narrative competence of SCH and ASD is investigated in reference to the crucial role of the representation of events, an opposite phenotype between the two conditions emerges. In 
people with ASD the atypical representation of events can be ascribed to an anchoring deficit, which results in a super focus on the details constituting an event. As pointed out above (following Benítez-Burraco and Progovac 2021), ASD is characterized by impoverished global connectivity in the cortico-striatal networks, but also by enhanced local connectivity, which is responsible for their sharper attention to detail. This general characterization can also help explain the bias in their narratives, leading individuals with ASD to process information locally focusing on details, while failing to integrate them into a wider global context (Happé et al. 2001) - details of events seem to exert a strong attractive power that prevents ASD from passing from the particular to the global scene of the story. This anchoring deficit might be brought into play to account for alterations in the use of anaphoric pronouns often observed in ASD (e.g., Colle et al., 2008).

Given this view, with ASD narratives one can expect to find super-focus, associated with a heightened attention to detail, perhaps with some (compulsive) repetitions. In support of this, Jolliffe and Baron-Cohen (2000) showed that the tendency to focus on details makes it difficult for people with ASD to integrate the constituent events of a story into a higher-order sequence: anchored to the details of the scenario, subjects with ASD struggle to connect one event to another and, therefore, to build the sequence of events into a story (see also Nuske and Bavin 2011; Adornetti et al., 2020). As also pointed out in Ferretti and colleagues (2018), although the causes of narrative problems in ASD are probably multiple, one of them may be a lack of imagination. Results of this study revealed that children with ASD who were asked to imagine the possible future or past episodes with respect to the target stimuli tended to persist on describing the elements included in the pictures' stimuli (super-focus) rather than introducing novel events connected to the pictures' stimuli, as the children of the control group did. Similarly, Marini and colleagues (2020) found that children with ASD who were administered 
a narrative description task produced fewer ideas than those depicted in the vignettes, suggesting a "significant difficulty ... in the phase of non-verbal conceptualization of the story" (p., 9). Overall, these findings are consistent with the proposal that ASD is characterized by an impairment, more precisely an inhibition, in the global connectivity of the relevant brain networks involved in cross-modality, while it shows a strength in local connectivity; both of these characteristics can be seen as yielding narratives which are super-focused on the details of events, but lacking in global cohesion.

In our view, SCH presents with an opposite pattern, which follows from a different way of representing events and agency, i.e. from atypical sequencing of complex dynamic events (e.g. Zalla et al 2004; Zalla et al., 2006), which has repercussions on the narrative plan. In contrast to what happens in ASD, in SCH we observe narratives with an unfocused, scattered, wildly metaphorical and imaginative style. The speech of SCH individuals is often described as disorganized and lacking focus (e.g. Kuperberg, 2010); as exhibiting "loose associations" (Chaika 1974; Nestor et al. 1998), and novel metaphors and novel words, including gibberish and neologisms (Chaika, 1974). All these symptoms may indeed have to do with uninhibited, enhanced cross-modality, as highlighted by Surguladze and colleagues (2002): in SCH "increased cross-modal connectivity (reduced modality modularity and informational encapsulation) between lexical representations ... could result in impaired language, particularly speech processing" (p. 884). For example, "loose associations" have to do with jumping from topic to topic, in such a way that to a typical language user seems incoherent, i.e. lacking in focus and sense (e.g. Kuperberg, 2010; Ankofski, 2018). Interestingly, sometimes the loose associations come from paying special attention to the meaning of a word from the previous utterance, rather than focusing on the overall topic (see e.g. Chaika 1974). ${ }^{6}$

\footnotetext{
${ }^{6}$ As one illustration, consider one SCH person's response to the question of what her mother's name was:
} 
In this respect, $\mathrm{SCH}$ can be seen as using super metaphorical language, with connections not obvious or acceptable, and thus interpreted as "word salad" or "gibberish" by a typical language user. Another interesting case in which the speech of persons with SCH is characterized by connections not obvious to others is when it relies on forms of clanging: "a pattern of speech in which sounds rather than meaningful relationships appear to govern word choice ... and redundant words are introduced. In addition to rhyming relationships, this pattern of speech may also include punning associations, so that a word similar in sound brings in a new thought" (McKenna and Oh, 2005, p. 23). Relevant for us, these forms of clanging echo typical synesthetic mechanisms. Nonetheless, the way individuals with $\mathrm{SCH}$ are using their language seems to be on a continuum with what metaphorical language generally affords, especially if we also consider poetry (see footnote 6).

So far, we have analyzed the nature of the narrative self in ASD and SCH in terms of a diametrical opposition between them, relating the impairments in both to atypical crossmodality. Considering that synesthesia is a condition characterized by super cross-modality (e.g. Cuskley and Kirby, 2013), the question arises as to what we can say about the construction of self in synesthesia. In the previous sections, we examined how different levels of selfawareness (senses of ownership and agency, self-other distinctions) can be impaired in certain kinds of synesthesia. While we can expect that a similar pattern of atypical narrative construction of the self will be observed in synesthesia, to the best of our knowledge, there are

My mother's name is Bill....and coo?

St. Valentine's Day is the startin' of breedin' season of birds.

All buzzards can coo.

I like to see it pronounced buzzard rightly.

They work hard. So do parakeets.

Responding with the name "Bill" causes the person to spontaneously utter the idiom, "bill and coo", which has romantic connotations. This seemingly takes the individual to mention Valentine's Day, a holiday centered around romance. On closer inspection, this string of sentences would probably not be considered unusual at all if found in a book of poetry. 
no studies investigating the narrative abilities, including the life stories, of synesthetes. That said, given that cross-modality seems to be directly involved in the representation of events, it is legitimate to hypothesize that an atypically enhanced cross-modality, such as that observed in synesthesia in general, might affect the narrative level in this respect, falling somewhere between ASD and SCH.

\section{Discussion and conclusions}

In this paper we have proposed that many of the issues with discourse experienced by people with SCH and ASD, and to some extent synesthesia as well, are related to problems with event representation in narratives, which in turn boil down to an altered sense of self. The novelty of our approach is in attributing the altered sense of self in all three conditions to the mechanism of cross-modality, which relies on a precise balance between inhibition and disinhibition in the connectivity in selected cortico-striatal brain networks, which also govern the suppression of (reactive) aggression in humans, and are responsible for syntactic and linguistic processing more generally, among several other functions. We further argued that this is the reason why all these dimensions cluster together in cognitive conditions like $\mathrm{SCH}, \mathrm{ASD}$, and synesthesia, and also why these conditions often present as different points (diametrically opposed in the case of SCH and ASD) within the continuum of the social brain, when it comes to: aggression management, metaphorical thinking, and language patterns, which are core features characterizing the cognitive and behavioral phenotype of the human species. These conclusions build on our previous research (Benítez-Burraco and Progovac, 2021; Benítez-Burraco et al., 2021), where we argued that a common neuronal substrate (i.e. enhanced connectivity in the cortico-striatal networks), and a common evolutionary cause (i.e. a gene-culture feedback loop, implicating HSD and the emergence of early grammars, e.g. Progovac and Benítez-Burraco, 2019) can be invoked to unify core aspects of language evolution that are usually treated 
independently: cross-modality, (verbal) aggression, structural language processing, and modern uses of language (including discourse abilities as found in present-day communication). In this paper, we have extended this paradigm to other cognitive and behavioral dimensions, particularly, the notion of the self and discourse practices.

With regards to ASD, the link between cross-modality and self-construction can be observed at different levels of analysis. In this paper, we considered the effects that atypical inhibition of cross-modality found in ASD has on the basic aspects of self, such as ownership, agency, and self-other differentiation. The reduced cross-modality characterizing ASD also has effects on the relationship between self and narratives. As we have seen, the representation of events in ASD appears impaired especially when it comes to the construction of a coherent sequence of events characterizing the global level of a story. Altered narratives of this kind by people with ASD can be linked to an atypical sense of self, which can in turn be related to diminished cross-modality and brain connectivity in cortico-striatal networks, but also associated with the diminished ability for MTT.

With regards to $\mathrm{SCH}$, the issues involving the fractured sense of self and atypical narrative structures in the stories created by people with this condition can be analyzed as related to their super cross-modality, attributed to the abnormally enhanced, disinhibited connectivity in the cortico-subcortical brain networks. This enhanced connectivity would lead not only to "loose associations" in speech and narratives, and to the excessive, somewhat chaotic use of pronouns, but also to hallucinations, i.e. surreal experiences (Silbersweig et al., 1995), which in turn lead to the surreal sense of who controls the actions, and thus to the shattered sense of self. In this way, our approach can unify the linguistic with non-linguistic symptoms of $\mathrm{SCH}$, providing a common cause. 
Synesthesia can shed further light on these phenomena, given that it is characterized as a condition exhibiting super cross-modality. According to Cuskley and Kirby (2013: 3), "synesthetes should be viewed as super cross-modal associators, with unusually strong, stable, and specific cross-modal biases." Importantly, the enhanced cross-modality in synesthesia has been ascribed to the hyper-connectivity of a synesthete's brain (Hanggi et al., 2011; Rouw et al., 2011; O'Dowd et al., 2019; Van Leeuwen et al., 2020). This is consistent with the observed parallels between synesthesia and $\mathrm{SCH}$, including vivid imagination which characterizes both, even though with $\mathrm{SCH}$ such imagination seems more severely blurred with reality. In this sense, various kinds of hallucinations experienced by individuals with $\mathrm{SCH}$ may be considered as more heightened, pathological states of synesthesia, as proposed in Benítez-Burraco and Progovac (2021). ${ }^{7}$ Conversely, as noted by Meier and Rothen (2013), the more vivid imagery visualizer style in synesthesia is consistent with reports of hallucinations and fantasizing (see also Banissy et al., 2012; 2013), and difficulties in dissociating dream imagery from reality (Meier and Rothen, 2013, 3). In fact, Banissy and colleagues (2012) found that synesthetes score higher on positive schizotypy.

As mentioned in section 2, synesthesia also sometimes presents with a disturbance in the sense of self. In order to highlight the link with cross-modality (and with the mechanism it relies on, i.e. enhanced brain connectivity), it is important to point out, as discussed mostly in section 2, that the typical construction and maintenance of self relies on a multi-modal/multi-sensory foundation, which is the essence of cross-modality. In the typical case, there seems to exist a delicate balance between maintaining a separate, integrated notion of self, and extending one's

\footnotetext{
${ }^{77}$ For other proposals and views regarding both overlaps and distinctions between synesthesia and SCH, see e.g. Van Leeuwen et al. (2020).
} 
self (in space and possibly time) to empathize with others, with these two different perspectives shifting with different contexts. In the atypical cases, as we propose, this balance is disturbed, in two diametrically opposed ways, which, moreover, can be linked to the disturbances in the mechanism of cross-modality.

On the one hand, super cross-modality can be seen as supporting enhanced empathy through an atypical extension of the self to others (a shattered sense of self, as found in SCH and some forms of synesthesia), but less ability to exit that perspective and solidify one's own sense of self as separate from others. This also seems to correlate with the excessive and chaotic use of pronouns in $\mathrm{SCH}$, as discussed in section 3. After all, the use of pronouns (I, you, she) is variable, and it is all about the relationships between self and others, while names (John, Maria) are more constant, more independent, and do not vary across contexts and perspectives. On the other hand, an atypical case of diminished, inhibited cross-modality, as attributed to ASD, shows the opposite effects on the construction and maintenance of self. In ASD, the sense of one's own self is more independent, and more separate from others, than in the typical case, which can be seen as correlated with a diminished degree of extension of one's self to others, and thus of empathy with others. This also can shed light on the opposite trend in the use of pronouns: while pronouns are used excessively in $\mathrm{SCH}$, they are often avoided in ASD, with e.g. the first person pronoun 'I' often being replaced by the name of the speaker. As pointed out above, names can stand independently and separately from others, while pronouns are constantly in a flux, and always in relation to another.

From what has been discussed in Section 4, it follows that the two processes characterizing the construction of the narrative plan - the relationship between events in the flow of discourse and event representation and agency - are both involved in the construction of the narrative 
identity and, consequently, in the explanation of some of the disturbances of the self in $\mathrm{SCH}$ and ASD, as characterized above. While clear differences do not seem to emerge between the two conditions when it comes to the former factor, i.e. the relationship between events, it is in reference to the latter factor, i.e. the representation of events and agency, that the view of ASD and $\mathrm{SCH}$ as diametrically opposed conditions can be maintained. Specifically, our proposal is that the different ways of representing events in ASD and SCH (and arguably in synesthesia as well) can be interpreted in reference to the atypical inhibition vs. disinhibition of the mechanism of cross-modality, necessary, among many other different functions, to support metaphorical extensions in language.

In other words, our proposal is that atypical features of narratives by people with SCH and ASD also result from altered cross-modality, and ultimately from altered connectivity in the cortico-striatal brain networks. As pointed out above, the impairment in narrative structure is also related to the altered sense of self, which in turn receives an explanation in the realm of cross-modality. Eventually, we expect that all these alterations result, at least in part, from an abnormal presentation of HSD features in these conditions. As shown in our previous work on SCH (Benítez-Burraco et al., 2017) and ASD (Benítez-Burraco et al., 2016), candidates for these conditions are enriched in genes involved in HSD. As HSD during human evolution contributed to an enhanced cross-modality via reduced reactive aggression (Benítez-Burraco and Progovac, 2021), our proposal here is that these evolutionary events in turn brought about a more modern representation of the self and more modern discourse forms and practices. Our hypothesis is thus that the mutation of selected genes that are candidates for SCH or ASD, but that are also involved in HSD, resulted in SCH or ASD symptoms via the deleterious effect of these mutations on the management of aggression and cross-modality, bringing about, 
specifically, an altered notion of self and problems with discourse more generally, as discussed in the paper.

At the same time, our proposal is not incompatible with some recent proposals relating MTT abilities to the hippocampus. For example, Corballis (2019) proposed that the evolutionary changes in the hippocampus contributed to an enhancement of our episodic memory, which allows us to mental travel both forward and backward in time, which in turn refined our creative imagination. As we argued in the previous sections, problems with mental travel, as well as with imagination, can be partly responsible for the atypical narrative structure in people with ASD and SCH. Complementary to Corballis' proposal, Benítez-Burraco (2021) has proposed to relate these evolutionary changes in the hippocampus to HSD, via the changes in the hippocampal function and size, which are associated with the changes in stress management, as features of HSD increased. In animals, including humans, the hippocampus is primarily involved in constructing spatial maps (Maguire et al., 1998; Vinogradova, 2001). In this sense, changes in the hippocampus and increased cross-modality i.e. enhanced connectivity in the cortico-subcortical brain circuits), both of which are linked to HSD, would have enabled humans to build upon this more primitive ability for spatial mental travel by (metaphorically) extending it to mental time travel.

How exactly the hippocampus can be integrated in this network is a question for future research to address. In our view, it is presently not possible to draw a clear distinction between the mechanisms behind cross-modality and the mechanisms behind MTT, in the construction of self in narratives: rather than being separate functions, they probably work closely together in the narrative processing underlying the construction of the narrative self. In fact, MTT can be seen as overlapping with cross-modality, particularly, when it comes to metaphoricity. This is 
so because the expression of time in natural languages, as well as conceptualization of time, is largely a metaphorical extension of space. In this respect, humans typically (but not always, as cultures can differ in this respect) perceive time as being linear, organized neatly on a line that has a dot for the Present moment, and then one treats events to the left of that dot as Past, and those to the right of that dot as Future. Languages routinely use metaphors of space to express time, in expressions such as "This issue is now behind us./It is no use looking back." Or "Better times are ahead of us." Prepositions that express movement toward something can be grammaticalized as future markers: e.g. English 'to' is used spatially in 'He walked to the store" but temporally in infinitives that imply future, such as "The president to visit China." In English one also talks about "long meetings," clearly using a spatial adjective, as found in e.g. "long lines." In addition, English "going to" is another grammaticalized metaphorical expression denoting future time, indicating both movement and the direction toward something, as evident in the contrast between its spatial use in "I am going to the store" and its temporal use in "I am going to faint" (for many more examples and patterns of metaphoricity, and its central role in language, see Lakoff and Johnson, 1980; for cultural aspects and differences in this regard, see Everett 2013). ${ }^{8}$

Accordingly, mental time maps can be regarded, to some extent, as metaphorical extensions of mental spatial maps. As a consequence, the problems that people with SCH and ASD experience with MTT can partly have to do with MTT needing to rely on metaphorical extension, which in turn relates to cross-modality and the connectivity of the brain. As pointed out in section 1, ASD individuals have a general problem with metaphorical extension, due to, as we have argued, to more limited access to the connectivity in the brain networks that support

\footnotetext{
${ }^{8}$ For metaphorical extensions in grammaticalization processes more generally, the reader is referred to e.g. Hopper and Traugott (2003); Heine and Kuteva (2007); Smith and Höfler (2014).
} 
cross-modality. On the other hand, the opposite seems to hold for $\mathrm{SCH}$, where an enhanced degree of disinhibition in these cortico-striatal networks seems to lead to unconstrained crossmodality, and with it to over-metaphorizing, and ultimately hallucinations and delusions. Last, but not least, the fact that HSD impacted on both hippocampal function and cross-modality provides additional support for the view of an interplay between cross-modality and MTT, and ultimately, between selected cortico-striatal circuits and the hippocampus. This issue certainly deserves further attention and elaboration, and we leave it for future research.

\section{References}

Abu-Akel, A. (2003). A neurobiological mapping of theory of mind. Brain research reviews, 43(1), 29-40.

Adornetti I. (2014) A Neuro-Cognitive Perspective on the Production and Comprehension of Discourse Coherence. In: Chruszczewski P., Rickford J., Buczek K., Knapik A., Mianowski J., Wacewicz S., Żywiczyński P. (Eds.), Ways to Protolanguage 3, Wydawnictwo WSF, Wrlowlac, pp. 9-24.

Adornetti, I., Chiera, A., Deriu, V., Altavilla, D., Lucentini, S., Marini, A., ... \& Ferretti, F. (2020). An investigation of visual narrative comprehension in children with autism spectrum disorders. Cognitive processing, 21(3), 435-447.

Adornetti I., Ferretti F. (2021) The narrative self in schizophrenia and its cognitive underpinnings. In V. Cardella \& A. Gangemi (eds.) Psychopatology and philosophy of mind. What mental disorders can tell us about our minds. Routledge, New York. pp. 96-116

Aimola-Davies, A. M., and White, R. C. (2013). A sensational illusion: vision-touch synaesthesia and the rubber hand paradigm. Cortex 49, 806-818. 
Allé, M. C., Potheegadoo, J., Köber, C., Schneider, P., Coutelle, R., Habermas, T., ... \& Berna, F. (2015). Impaired coherence of life narratives of patients with schizophrenia. Scientific reports, 5, 12934.

Allé, M. C., d'Argembeau, A., Schneider, P., Potheegadoo, J., Coutelle, R., Danion, J. M., \& Berna, F. (2016a). Self-continuity across time in schizophrenia: An exploration of phenomenological and narrative continuity in the past and future. Comprehensive psychiatry, 69, 53-61.

Allé, M. C., Gandolphe, M. C., Doba, K., Köber, C., Potheegadoo, J., Coutelle, R., ... \& Berna, F. (2016b). Grasping the mechanisms of narratives' incoherence in schizophrenia: an analysis of the temporal structure of patients' life story. Comprehensive psychiatry, 69 , 20-29.

Allen, P. P., Johns, L. C., Fu, C. H., Broome, M. R., Vythelingum, G. N., and McGuire, P. K. (2004). Misattribution of external speech in patients with hallucinations and delusions. Schizophrenia Research 69, 277-287.

Altavilla, D., Acciai, A., Deriu, V., Chiera, A., Adornetti, I., Ferretti, F., ... \& Canali, S. (2020). Linguistic Analysis of Self-Narratives of Patients With Gambling Disorder. Addictive Disorders \& Their Treatment, 19(4), 209-217.

Andreasen, N. C. (1979). Thought, language and communication disorders: II Diagnostic significance. Archives of General Psychiatry, 36, 1325-1330.

Ankofski, D (2018) Semantic Processing in Schizophrenia: The Effects Schizophrenia has on the Extended Wernicke's Area. MA essay, Wayne State University.

Arnaud, S. (2020). Self-consciousness in autism: A third-person perspective on the self. Mind \& Language. https://doi.org/10.1111/mila.12356

Asperger H. (1944) Die autistischen Psychopathen im Kindesalter, Archiv fur Psychiatrie und Nervenkrankheiten, 117, 76-136 
Bakhshi, K., \& Chance, S. A. (2015). The neuropathology of schizophrenia: a selective review of past studies and emerging themes in brain structure and cytoarchitecture. Neuroscience, 303, 82-102.

Baldwin, J. M. (1902). Social and ethical interpretations in mental development. New York: Macmillan

Banker, S. M., Gu, X., Schiller, D., \& Foss-Feig, J. H. (2021). Hippocampal contributions to social and cognitive deficits in autism spectrum disorder. Trends in neurosciences, 44(10), 793-807.

Banissy, M. J., Kadosh, R. C., Maus, G. W., Walsh, V., \& Ward, J. (2009). Prevalence, characteristics and a neurocognitive model of mirror-touch synaesthesia. Experimental brain research, 198(2-3), 261-272.

Banissy, M. J., Cassell, J. E., Fitzpatrick, S., Ward, J., Walsh, V. X., \& Muggleton, N. G. (2012). Increased positive and disorganised schizotypy in synaesthetes who experience colour from letters and tones. Cortex, 48(8), 1085-1087.

Banissy, M. J., \& Ward, J. (2013). Mechanisms of self-other representations and vicarious experiences of touch in mirror-touch synesthesia. Frontiers in human neuroscience, 7 , 112.

Baron-Cohen S. (2005) Autism - 'autos': Literally, a total focus on the self? In: Feinberg TE, Keenan JP (Eds) The lost self: pathologies of the brain and identity. Oxford: Oxford University Press.

Baron-Cohen, S. (2009). Autism: the empathizing-systemizing (ES) theory. Annals of the New York Academy of Sciences, 1156(1), 68-80.

Baron-Cohen, S., Harrison, J., Goldstein, L. H., \& Wyke, M. (1993). Coloured speech perception: Is synaesthesia what happens when modularity breaks down?. Perception, 22(4), 419-426. 
Barokova, M., \& Tager-Flusberg, H. (2020). Person-reference in autism spectrum disorder: Developmental trends and the role of linguistic input. Autism Research, 13(6), 959-969.

Bailey A, Phillips W, Rutter M (1996) Autism: towards an integration of clinical, genetic, neuropsychological, and neurobiological perspectives. J. Child Psychol. Psychiatry 37(1): 89-126.

Benítez-Burraco, A. (2021). Mental time travel, language evolution, and human selfdomestication. Cognitive Processing, 22(2), 363-367.

Benítez-Burraco A, Ferretti F and Progovac L. (2021) Human self-domestication, pragmatics, and language evolution. Cognitive Science. 45(6), e12987,1-39

Benítez-Burraco A, Lattanzi W, Murphy E. (2016) Language impairments in ASD resulting from a failed domestication of the human brain. Frontiers in Neurosciences, 10, 373. (doi:10.3389/fnins.2016.00373)

Benítez-Burraco A, Di Pietro L, Barba M, Lattanzi W. 2017 Schizophrenia and human selfdomestication: an evolutionary linguistics approach. Brain Behav. Evol. 89, 162-184. (doi:10.1159/000468506)

Benítez-Burraco, A., \& Progovac, L. (2020). A four-stage model for language evolution under the effects of human self-domestication. Language \& Communication, 73, 1-17.

Benítez-Burraco A, Progovac L. 2021 Language evolution: examining the link between crossmodality and aggression through the lens of disorders. Philosophical Transactions of the Royal Society B, 376: 20200188. https://doi.org/10.1098/rstb.2020.0188

Blakemore, S. J., Bristow, D., Bird, G., Frith, C., \& Ward, J. (2005). Somatosensory activations during the observation of touch and a case of vision-touch synaesthesia. Brain, 128(7), 1571-1583.

Bleuler, E. (1911). Dementia Praecox or the Group of Schizophrenias. Translated by J. Zinkin. New York, NY: International Universities Press, 1950 
Bo S, Forth A, Kongerslev M, Haahr UH, Pedersen L, Simonsen E. 2013 Subtypes of aggression in patients with schizophrenia: the role of psychopathy. J. Forensic Psychiat. Psychol. 24, 496-513. (doi:10.1080/14789949.2013.809468)

Bolognini, N., Miniussi, C., Gallo, S., \& Vallar, G. (2013). Induction of mirror-touch synaesthesia by increasing somatosensory cortical excitability. Current Biology, 23(10), R436-R437.

Botvinick, M., \& Cohen, J. (1998). Rubber hands 'feel'touch that eyes see. Nature, 391(6669), 756-756.

Boudewyn, M. A., Carter, C. S., and Swaab, T. Y. (2012). Cognitive control and discourse comprehension in schizophrenia. Schizophr. Res. Treat. 2012, 484-502

Boudewyn, M. A., Carter, C. S., Long, D. L., Traxler, M. J., Lesh, T. A., Mangun, G. R., \& Swaab, T. Y. (2017). Language context processing deficits in schizophrenia: The role of attentional engagement. Neuropsychologia, 96, 262-273.

Bruner, J. (1975). From communication to language. A psychological perspective. Cognition, $3,255-287$

Bruner, J. (1997). A narrative model of self-construction. Annals of the New York Academy of Sciences, 818(1), 145-161.

Bruner, J. (2003). Self-making narratives. In Autobiographical memory and the construction of a narrative self (pp. 225-242). Psychology Press.

Bruner, J. (2004). The narrative creation of self. In L. Angus \& J. McLeod (Eds.), The handbook of narrative and psychotherapy: Practice, theory, and research (pp. 3-14). Thousand Oaks, CA: Sage

Buck, B. \& Penn, D. L. 2015 Lexical characteristics of emotional narratives in schizophrenia: relationships with symptoms, functioning, and social cognition. J. Nerv. Ment. Dis. 203, 702-708 (2015). 
Buck, B., Minor, K. S., \& Lysaker, P. H. (2015). Differential lexical correlates of social cognition and metacognition in schizophrenia; a study of spontaneously-generated life narratives. Comprehensive psychiatry, 58, 138-145.

Burrows, C. A., Usher, L. V., Mundy, P. C. \& Henderson, H. A. (2017). The salience of the self: Self-referential processing and internalizing problems in children and adolescents with autism spectrum disorder. Autism Research, 10(5), 949-960

Cachia, A., Cury, C., Brunelin, J., Plaze, M., Delmaire, C., Oppenheim, C., ... \& Jardri, R. (2020). Deviations in early hippocampus development contribute to visual hallucinations in schizophrenia. Translational psychiatry, 10(1), 1-7.

Canali, S., Altavilla, D., Acciai, A., Deriu, V., Chiera, A., Adornetti, I., ... \& Ferretti, F. (2021). The Narrative of Persons with Gambling Problems and Substance Use: A Multidimensional Analysis of the Language of Addiction. Journal of Gambling Issues, (47), 167-198

Cannon, T. D. (2015). How schizophrenia develops: cognitive and brain mechanisms underlying onset of psychosis. Trends in cognitive sciences, 19(12), 744-756.

Chaika, E. (1974). A linguist looks at "schizophrenic" language. Brain and Language 1.

Chen, X. J., Liu, L. L., Cui, J. F., Wang, Y., Chen, A. T., Li, F. H., ... \& Shum, D. H. (2016). Schizophrenia spectrum disorders show reduced specificity and less positive events in mental time travel. Frontiers in psychology, 7, article 1121

Cioffi, M. C., Banissy, M. J., \& Moore, J. W. (2016). 'Am I moving?’An illusion of agency and ownership in mirror-touch synaesthesia. Cognition, 146, 426-430.

Cohn-Sheehy, B. I., Delarazan, A. I., Reagh, Z. M., Crivelli-Decker, J. E., Kim, K., Barnett, A. J., ... \& Ranganath, C. (2021). The hippocampus constructs narrative memories across distant events. Current Biology, 31, 1-11. 
Colle, L., Baron-Cohen, S., Wheelwright, S., \& Van Der Lely, H. K. (2008). Narrative discourse in adults with high-functioning autism or Asperger syndrome. Journal of autism and developmental disorders, 38(1), 28-40.

Cooley, C. H. (1902). Human nature and the social order. New York: Scribner

Cook, J. L., \& Bird, G. (2012). Atypical social modulation of imitation in autism spectrum conditions. Journal of autism and developmental disorders, 42(6), 1045-1051.

Corballis, M. C. (2019). Mental time travel, language, and evolution. Neuropsychologia, 134, 107202.

Cosentino, E. (2011). Self in time and language. Consciousness and cognition, 20(3), 777-783.

Crespi B.J. (2008) Language unbound: genomic conflict and psychosis in the origin of modern humans. In Social communication (eds D Hughes, P D’Ettorre). Oxford, UK: Oxford University Press.

Crespi B, Badcock C. 2008 Psychosis and autism as diametrical disorders of the social brain. Behavioral and Brain Science, 31, 241-261. (doi:10.1017/S0140525X08004214)

Cuervo-Lombard, C., Jovenin, N., Hedelin, G. U. Y., Rizzo-Peter, L., Conway, M. A., \& Danion, J. M. (2007). Autobiographical memory of adolescence and early adulthood events: An investigation in schizophrenia. Journal of the International Neuropsychological Society, 13(2), 335-343.

Cuskley C, Kirby S (2013) Synaesthesia, cross-modality and language evolution. Oxford Handbook of Synaesthesia, eds Simner J, Hubbard EM (Oxford Univ Press, Oxford, UK), pp 869-907

Cytowic RE. (1993) The man who tasted shapes: a bizarre medical mystery offers revolutionary insights into emotions, reasoning, and consciousness. New York, NY: GP Putnam's Sons 
Cytowic, R. E. (2002). Synesthesia: A Union of the Senses (2nd edition). Cambridge, Massachusetts: MIT Press.

Cytowic, R. E., and Eagleman, D. M. (2009). Wednesday is Indigo Blue: Discovering the Brain of Synesthesia (with an afterword by Dmitri Nabokov). Cambridge: MIT Press.

Dager, S. R., Wang, L., Friedman, S. D., Shaw, D. W., Constantino, J. N., Artru, A. A., ... \& Csernansky, J. G. (2007). Shape mapping of the hippocampus in young children with autism spectrum disorder. American journal of neuroradiology, 28(4), 672-677.

D'Argembeau, A., Raffard, S., \& Van der Linden, M. (2008). Remembering the past and imagining the future in schizophrenia. Journal of abnormal psychology, 117(1), 247251.

David, N., Gawronski, A., Santos, N. S., Huff, W., Lehnhardt, F. G., Newen, A., \& Vogeley, K. (2008). Dissociation between key processes of social cognition in autism: Impaired mentalizing but intact sense of agency. Journal of Autism and Developmental Disorders, 38(4), 593-605.

Decety, J., \& Chaminade, T. (2003). When the self represents the other: A new cognitive neuroscience view on psychological identification. Consciousness and cognition, 12(4), 577-596.

De Guzman, M., Bird, G., Banissy, M. J., \& Catmur, C. (2016). Self-other control processes in social cognition: from imitation to empathy. Philosophical Transactions of the Royal Society B: Biological Sciences, 371(1686), 20150079.

Dehaene, S. (2014). Consciousness and the brain: Deciphering how the brain codes our thoughts. New York, Penguin

Delevoye-Turrell, Y., Vienne, C., \& Coello, Y. (2011). Space boundaries in schizophrenia. Social Psychology, 42(3)

Dennett, D. C. (1991). Consciousness Explained. Boston MA: Little Brown and Company. 
de Villiers, P. A., \& de Villiers, J. G. (1974). On this, that, and the other: Nonegocentrism in very young children. Journal of Experimental Child Psychology, 18(3), 438-447.

Diehl, J. J., Bennetto, L., \& Young, E. C. (2006). Story recall and narrative coherence of highfunctioning children with autism spectrum disorders. Journal of abnormal child psychology, 34(1), 83-98.

Di Francesco, M., Marraffa, M., \& Paternoster, A. (2016). The self and its defenses. From Psychodynamics to Cognitive Science. London: Palgrave McMillan

Ditman, T., \& Kuperberg, G. R. (2007). The time course of building discourse coherence in schizophrenia: an ERP investigation. Psychophysiology, 44(6), 991-1001.

Dodd S. (2005) Understanding autism. Marrickville, Australia: Elsevier Australia.

Duff, M. C., Hengst, J. A., Tranel, D., \& Cohen, N. J. (2008). Collaborative discourse facilitates efficient communication and new learning in amnesia. Brain and language, 106(1), 4154.

Eddy, C. M. (2018). Social cognition and self-other distinctions in neuropsychiatry: insights from schizophrenia and Tourette syndrome. Progress in Neuro-Psychopharmacology and Biological Psychiatry, 82, 69-85.

Everett, Caleb. (2013). Linguistic Relativity: Evidence Across Languages and Cognitive Domains. Berlin: de Gruyter.

Ferretti, F., Adornetti, I., Chiera, A., Nicchiarelli, S., Valeri, G., Magni, R., Vicari S., \& Marini, A. (2018). Time and narrative: an investigation of storytelling abilities in children with autism spectrum disorder. Frontiers in psychology, 9, 944.

Ferri, F., Frassinetti, F., Mastrangelo, F., Salone, A., Ferro, F. M., \& Gallese, V. (2012). Bodily self and schizophrenia: the loss of implicit self-body knowledge. Consciousness and cognition, 21(3), 1365-1374. 
Ferri, F., Costantini, M., Salone, A., Di Iorio, G., Martinotti, G., Chiarelli, A., ... \& Gallese, V. (2014). Upcoming tactile events and body ownership in schizophrenia. Schizophrenia Research, 152(1), 51-57.

Fineberg, S. K., Leavitt, J., Deutsch-Link, S., Dealy, S., Landry, C. D., Pirruccio, K., ... \& Corlett, P. R. (2016). Self-reference in psychosis and depression: a language marker of illness. Psychological medicine, 46(12), 2605-2615.

Fink, A., Benedek, M., Unterrainer, H. F., Papousek, I., \& Weiss, E. M. (2014). Creativity and psychopathology: are there similar mental processes involved in creativity and in psychosis-proneness?. Frontiers in psychology, 5, 1211.

Finnegan, E. G., Asaro-Saddler, K., \& Zajic, M. C. (2021). Production and comprehension of pronouns in individuals with autism: A meta-analysis and systematic review. Autism, 25(1), 3-17.

Fitzpatrick SE, Srivorakiat L, Wink LK, Pedapati EV, Erickson CA. 2016 Aggression in autism spectrum disorder: presentation and treatment options. Neuropsychiatr. Dis. Treat. 12, 1525-1538. (doi:10.2147/NDT.S84585)

Fornara, G. A., Papagno, C., \& Berlingeri, M. (2017). A neuroanatomical account of mental time travelling in schizophrenia: a meta-analysis of functional and structural neuroimaging data. Neuroscience \& Biobehavioral Reviews, 80, 211-222.

Frith, C. D. (1992). The cognitive neuropsychology of schizophrenia. New York: Psychology press

Frith, C. (2002). Attention to action and awareness of other minds. Consciousness and cognition, 11(4), 481-487.

Frith, C. D., \& Done, D. J. (1989). Experiences of alien control in schizophrenia reflect a disorder in the central monitoring of action. Psychological medicine, 19(2), 359-363. 
Frith, C. D., Blakemore, S. J., \& Wolpert, D. M. (2000). Explaining the symptoms of schizophrenia: abnormalities in the awareness of action. Brain Research Reviews, 31(23), 357-363.

Frith, U. \& De Vignemont, F. (2005). Egocentrism, allocentrism, and Asperger syndrome. Consciousness and Cognition, 14(4), 719-738.

Frith, U., \& Happé, F. (1999). Theory of mind and self-consciousness: What is it like to be autistic?. Mind \& language, 14(1), 82-89.

Gallagher, S. (2000). Philosophical conceptions of the self: implications for cognitive science. Trends in cognitive sciences, 4(1), 14-21.

Gallagher, S., \& Shear, J. (Eds.). (1999). Models of the Self. Thorverton, UK: Imprint Academic

Gallagher, S., \& Zahavi, D. (2012). The Phenomenological Mind. London: Routledge

Gallese, V., \& Ferri, F. (2014). Psychopathology of the bodily self and the brain: the case of schizophrenia. Psychopathology, 47(6), 357-364.

Garbarini, F., Mastropasqua, A., Sigaudo, M., Rabuffetti, M., Piedimonte, A., Pia, L., \& Rocca, P. (2016). Abnormal sense of agency in patients with schizophrenia: Evidence from bimanual coupling paradigm. Frontiers in Behavioral Neuroscience, 10, 43.

Gärdenfors, P. (2000). Conceptual spaces: The geometry of thought. Cambridge: MIT press.

Gardenfors, P. (2014). The geometry of meaning: Semantics based on conceptual spaces. Cambridge: MIT press.

Genette G (1972) Discours du Récit, Essai de Méthode, vol III. Paris: Seouil.

Giddens, A. (1991) Modernity and Self-identity: Self and Society in the Late Modern Age. Cambridge: Polity.

Grossenbacher, P. G., \& Lovelace, C. T. (2001). Mechanisms of synesthesia: cognitive and physiological constraints. Trends in cognitive sciences, 5(1), 36-41. 
Habermas, T., \& de Silveira, C. (2008). The development of global coherence in life narratives across adolescence: Temporal, causal, and thematic aspects. Developmental Psychology,44, 707-721

Habermas, T., \& Köber, C. (2014). Autobiographical reasoning is constitutive for narrative identity: The role of the life story for personal continuity. In K. C. McLean \& M. U. Syed (Eds.), The Oxford handbook of identity development (pp. 1-33). New York, NY: Oxford University Press.

Haggard, P. (2017). Sense of agency in the human brain. Nature Reviews Neuroscience, 18(4), 196-207.

Hänggi, J., Wotruba, D., \& Jäncke, L. (2011). Globally altered structural brain network topology in grapheme-color synesthesia. Journal of Neuroscience, 31(15), 5816-5828.

Happé, F., \& Frith, U. (2006). The weak coherence account: detail-focused cognitive style in autism spectrum disorders. Journal of autism and developmental disorders, 36(1), 525.

Happé, F., Frith, U., \& Briskman, J. (2001). Exploring the cognitive phenotype of autism: weak "central coherence" in parents and siblings of children with autism: I. Experimental tests. The Journal of Child Psychology and Psychiatry and Allied Disciplines, 42(3), 299-307.

Hare B. 2017 Survival of the friendliest: Homo sapiens evolved via selection for prosociality. Annual Review of Psychology, 68, 155-186. (doi:10.1146/annurevpsych-010416044201)

Hare, B., \& Woods, V. (2020). Survival of the friendliest: Understanding our origins and rediscovering our common humanity. New York: Penguin Random House.

Harrington, L., Siegert, R., \& McClure, J. (2005). Theory of mind in schizophrenia: a critical review. Cognitive neuropsychiatry, 10(4), 249-286. 
Heine, B. and Kuteva, T. (2007). The genesis of Grammar. Oxford: Oxford University Press. Henriksen, M. G., \& Nordgaard, J. (2014). Schizophrenia as a disorder of the self. Journal of Psychopathology, 20, 435-441.

Hill AP, Zuckerman KE, Hagen AD, Kriz DJ, Duvall SW, van Santen J, Nigg J, Fair D, Fombonne E. 2014. Aggressive behavior problems in children with autism spectrum disorders: prevalence and correlates in a large clinical sample. Res. Autism Spectr. Disord. 8, 1121-1133. (doi:10.1016/j.rasd.2014.05.006)

Hobson, R. P. (1990). On the origins of self and the case of autism. Development and Psychopathology, 2(2), 163-181.

Hobson PR, Chidambi G, Lee A, Meyer J. Foundations for self-awareness: an exploration through autism, Monogr Soc Res Child Dev, 2006, vol. 71

Hobson, R. P., Lee, A., \& Hobson, J. A. (2010). Personal pronouns and communicative engagement in autism. Journal of autism and developmental disorders, 40(6), 653-664.

Hofmann, W., Schmeichel, B. J., \& Baddeley, A. D. (2012). Executive functions and selfregulation. Trends in cognitive sciences, 16(3), 174-180.

Holle, H., Banissy, M. J., \& Ward, J. (2013), Functional and Structural Brain Differences Associated with Mirror-touch Synaesthesia, Neuroimage 83: 1041-1050.

Hopper, P. J. and Traugott, E. C. (2003). Grammaticalization. Cambridge: Cambridge University Press.

Hubbard, E. M. (2007). Neurophysiology of synesthesia. Current psychiatry reports, 9(3), 193199.

Hubbard, E. M., \& Ramachandran, V. S. (2005). Neurocognitive mechanisms of synesthesia. Neuron, 48(3), 509-520.

Hur, J. W., Kwon, J. S., Lee, T. Y., \& Park, S. (2014). The crisis of minimal self-awareness in schizophrenia: a meta-analytic review. Schizophrenia research, 152(1), 58-64. 
Hurlburt RT, Happe F, Frith U. (1994) Sampling the form of inner experience in three adults with Asperger syndrome, Psychol Med, 24, 385-95

Ioumpa, K., Graham, S. A., Clausner, T., Fisher, S. E., Van Lier, R., \& Van Leeuwen, T. M. (2019). Enhanced self-reported affect and prosocial behaviour without differential physiological responses in mirror-sensory synaesthesia. Philosophical Transactions of the Royal Society B, 374(1787), 20190395.

Jeannerod, M. (2007). From my self to other selves: A revised framework for the self/other differentiation. Sensorimotor foundations of higher cognition, 233-248.

Jeannerod, M. (2009). The sense of agency and its disturbances in schizophrenia: a reappraisal. Experimental Brain Research, 192(3), 527-532.

Jolliffe, T., \& Baron-Cohen, S. (2000). Linguistic processing in high-functioning adults with autism or Asperger's syndrome. Is global coherence impaired?. Psychological medicine, 30(5), 1169-1187.

Jordan, R. R. (1989). An experimental comparison of the understanding and use of speakeraddressee personal pronouns in autistic children. International Journal of Language \& Communication Disorders, 24(2), 169-179.

Jordan, R. (2010). Autism Spectrum Disorders: An Introductory Handbook for Practitioners. Oxfordshire: David Fulton Publishers.

Kambanaros, M., Christou, N., \& Grohmann, K. K. (2019). Interpretation of compound words by Greek-speaking children with autism spectrum disorder plus language impairment (ASD-LI). Clinical linguistics \& phonetics, 33(1-2), 135-174.

Kanner, L. (1943). Autistic disturbances of affective contact. Nervous child, 2(3), 217-250.

Kean C. (2009) Silencing the self: schizophrenia as a self-disturbance. Schizophrenia Bullettin, 35(6):1034-1036

Kerns, J. G. (2007). Verbal communication impairments and cognitive control components in 
people with schizophrenia. Journal of Abnormal Psychology, 116(2), 279.

Kerns, J. G., \& Berenbaum, H. (2002). Cognitive impairments associated with formal thought disorder in people with schizophrenia. Journal of abnormal psychology, 111(2), 211.

King, D., Dockrell, J., \& Stuart, M. (2014). Constructing fictional stories: a study of story narratives by children with autistic spectrum disorder. Research in developmental disabilities, 35(10), 2438-2449.

Kinzler, K. D., \& Spelke, E. S. (2007). Core systems in human cognition. Progress in brain research, 164, 257-264.

Kuang, S. (2016). Toward a unified social motor cognition theory of understanding mirrortouch synaesthesia. Frontiers in human neuroscience, 10, 246.

Kuperberg, G. (2010). Language in schizophrenia part 1: An introduction. Lang Linguist Compass 4(8), 576-589.

Kutas, M., \& Hillyard, S. A. (1980). Reading senseless sentences: Brain potentials reflect semantic incongruity. Science, 207(4427), 203-205.

Kutas, M., \& Federmeier, K. D. (2011). Thirty years and counting: finding meaning in the N400 component of the event-related brain potential (ERP). Annual review of psychology, 62, 621-647.

Lakoff, G. and Johnson, M. (1980). Metaphors we live by. Chicago: University of Chicago.

Lee, A., Hobson, R. P., \& Chiat, S. (1994). I, you, me, and autism: An experimental study. Journal of autism and developmental disorders, 24(2), 155-176.

Li, Q., Cheung, C., Wei, R., Hui, E. S., Feldon, J., Meyer, U., ... \& McAlonan, G. M. (2009). Prenatal immune challenge is an environmental risk factor for brain and behavior change relevant to schizophrenia: evidence from MRI in a mouse model. PloS one, 4(7), e6354. 
Lewis, M., \& Mehling, D. (2004). Development of self-recognition, personal pronoun use, and pretend play during the 2nd year. Child development, 75(6), 1821-1831.

Liepelt, R., Schneider, J. C., Aichert, D. S., Wöstmann, N., Dehning, S., Möller, H. J., ... \& Ettinger, U. (2012). Action blind: disturbed self-other integration in schizophrenia. Neuropsychologia, 50(14), 3775-3780.

Lombardo, M. V., Barnes, J. L., Wheelwright, S. J., \& Baron-Cohen, S. (2007). Self-referential cognition and empathy in autism. PloS one, 2(9), e883.

Lombardo, M. V., \& Baron-Cohen, S. (2010). Unraveling the paradox of the autistic self. Wiley Interdisciplinary Reviews: Cognitive Science, 1(3), 393-403.

Lombardo, M. V., Chakrabarti, B., Bullmore, E. T., Sadek, S. A., Pasco, G., Wheelwright, S. J., ... \& Baron-Cohen, S. (2010). Atypical neural self-representation in autism. Brain, 133(2), 611-624.

Losh, M., \& Capps, L. (2003). Narrative ability in high-functioning children with autism or Asperger's syndrome. Journal of autism and developmental disorders, 33(3), 239-251.

Lyons, V., \& Fitzgerald, M. (2013). Atypical sense of self in autism spectrum disorders: a neuro-cognitive perspective. In Recent Advances in Autism Spectrum DisordersVolume I. IntechOpen.

Lyons, A. D., Henry, J. D., Rendell, P. G., Robinson, G., \& Suddendorf, T. (2016). Episodic foresight and schizophrenia. British Journal of Clinical Psychology, 55(2), 107-122.

Lysaker, P. H., \& Lysaker, J. T. (2010). Schizophrenia and alterations in self-experience: a comparison of 6 perspectives. Schizophrenia bulletin, 36(2), 331-340.

Lysaker, P. H., Olesek, K. L., Warman, D. M., Martin, J. M., Salzman, A. K., Nicolò, G., ... \& Dimaggio, G. (2011). Metacognition in schizophrenia: Correlates and stability of deficits in theory of mind and self-reflectivity. Psychiatry Research, 190(1), 18-22. 
MacKay, D. G., Burke, D. M., \& Stewart, R. (1998). H.M.'s language production deficits: implications for relations between memory, semantic binding, and the hippocampal system. Journal of Memory and Language, 38, $28 \mathrm{e} 69$.

MacKay, D. G., James, L. E., Taylor, J. K., \& Marian, D. E. (2007). Amnesic H.M. exhibits parallel deficits and sparing in language and memory: systems versus binding theory accounts. Language and Cognitive Processes, 22(3), 377e452.

Mackinley, M., Chan, J., Ke, H., Dempster, K., \& Palaniyappan, L. (2021). Linguistic determinants of formal thought disorder in first episode psychosis. Early intervention in psychiatry, 15(2), 344-351.

Maguire EA, Burgess N, Donnett JG, Frackowiak RS, Frith CD, O’Keefe J (1998) Knowing where and getting there: a human navigation network. Science 280(5365):921-924.

Maguire, E. A., Intraub, H., \& Mullally, S. L. (2016). Scenes, spaces, and memory traces: what does the hippocampus do?. The Neuroscientist, 22(5), 432-439.

Maister, L., Banissy, M. J., \& Tsakiris, M. (2013). Mirror-touch synaesthesia changes representations of self-identity. Neuropsychologia, 51(5), 802-808.

Malek, H. B., D’Argembeau, A., Allé, M. C., Meyer, N., Danion, J. M., \& Berna, F. (2019). Temporal processing of past and future autobiographical events in patients with schizophrenia. Scientific reports, 9(1), 1-11.

Marini, A., Spoletini, I., Rubino, I. A., Ciuffa, M., Bria, P., Martinotti, G., ... \& Spalletta, G. (2008). The language of schizophrenia: An analysis of micro and macrolinguistic abilities and their neuropsychological correlates. Schizophrenia research, 105(1-3), 144-155.

Marini, A., Ferretti, F., Chiera, A., Magni, R., Adornetti, I., Nicchiarelli, S., ... \& Valeri, G. (2019). Episodic future thinking and narrative discourse generation in children with Autism Spectrum Disorders. Journal of Neurolinguistics, 49, 178-188. 
Marini, A., Ozbič, M., Magni, R., \& Valeri, G. (2020). Toward a definition of the linguistic profile of children with autism spectrum disorder. Frontiers in psychology, 11, 808.

Maurer D. (1993) Neonatal synesthesia: implications for the processing of speech and faces. In NATO ASI series D: behavioural and social sciences, vol. 69 (eds B de BoyssonBardies, S de Schonen, PW Jusczyk, P McNeilage, J Morton), pp. 109-124. Dordrecht, The Netherlands: Kluwer Academic/Plenum Publishers.

Maurer, D., \& Mondloch, C. J. (2006). The infant as synesthete. Attention and Performance, $21,449-471$.

McAdams, D. P. (2001). The psychology of life stories. Review of General Psychology,5, 100122.

McAdams, D. P., \& McLean, K. C. (2013). Narrative identity. Current Directions in Psychological Science, 22, 233-238. https://doi.org/10.1177/0963721413475622

McCabe, A., Hillier, A., \& Shapiro, C. (2013). Brief report: Structure of personal narratives of adults with autism spectrum disorder. Journal of autism and developmental disorders, 43(3), 733-738.

McKenna, P. J., \& Oh, T. M. (2005). Schizophrenic speech: Making sense of bathroots and ponds that fall in doorways. Cambridge: Cambridge University Press.

Mead, G. H. (1934). Mind, self, and society (C. W. Morris, Ed.). Chicago: University of Chicago Press

Mehling, W. E., Gopisetty, V., Daubenmier, J., Price, C. J., Hecht, F. M., \& Stewart, A. (2009). Body awareness: construct and self-report measures. PloS one, 4(5), e5614.

Meltzoff, A. N. (1990). Foundations for developing a concept of self: The role of imitation in relating self to other and the value of social mirroring, social modeling, and self practice in infancy. In D. Cicchetti \& M. Beeghly (Eds.), The self in transition: Infancy to childhood (pp. 139 - 164). Chicago: University of Chicago Press. 
Michael, J., \& Park, S. (2016). Anomalous bodily experiences and perceived social isolation in schizophrenia: an extension of the social deafferentation hypothesis. Schizophrenia research, 176(2-3), 392-397.

Milivojevic, B., Varadinov, M., Grabovetsky, A. V., Collin, S. H., \& Doeller, C. F. (2016). Coding of event nodes and narrative context in the hippocampus. Journal of Neuroscience, 36(49), 12412-12424.

Moyer, M., Harrigan, K., Hacquard, V., \& Lidz, J. (2015). 2-year-olds' comprehension of personal pronouns. In Online Supplemental Proceedings of the 39th Boston University Conference on Language Development.

Nasrallah, H.A. (2012) Impaired mental proprioception in schizophrenia. Editorial. Current Psychiatry 11.8: 4-5.

Neisser, U. (1988). Five kinds of self-knowledge. Philosophical Psychology, 1, 35-59

Nelson, B., Fornito, A., Harrison, B. J., Yücel, M., Sass, L. A., Yung, A. R., ... \& McGorry, P. D. (2009). A disturbed sense of self in the psychosis prodrome: linking phenomenology and neurobiology. Neuroscience \& Biobehavioral Reviews, 33(6), 807-817.

Nestor, P., Akdag, S., O’Donnell, B., Niznikiewicz, M., Law, S., Shenton, M., \& McClarley, R. (1998). Word recall in schizophrenia: A connectionist model. Am J Psychiatry 155.

Nieuwland, M. S., \& Van Berkum, J. J. (2006). When peanuts fall in love: N400 evidence for the power of discourse. Journal of cognitive neuroscience, 18(7), 1098-1111.

Noel, J.-P., Cascio, C. J., Wallace, M. T. \& Park, S. (2017). The spatial self in schizophrenia and autism spectrum disorder. Schizophrenia Research, 179, 8-12

Novogrodsky, R. (2013). Subject pronoun use by children with autism spectrum disorders (ASD). Clinical linguistics \& phonetics, 27(2), 85-93. 
Novogrodsky, R., \& Edelson, L. R. (2016). Ambiguous pronoun use in narratives of children with Autism Spectrum Disorders. Child Language Teaching and Therapy, 32(2), 241252.

Nuske, H. J., \& Bavin, E. L. (2011). Narrative comprehension in 4-7-year-old children with autism: testing the Weak Central Coherence account. International Journal of Language \& Communication Disorders, 46:108-119

O'Dowd, A., Cooney, S. M., McGovern, D. P., \& Newell, F. N. (2019). Do synaesthesia and mental imagery tap into similar cross-modal processes?. Philosophical Transactions of the Royal Society B, 374(1787), 20180359.

Palaniyappan, L. (2021). More than a biomarker: could language be a biosocial marker of psychosis?. npj Schizophrenia, 7(1), 1-5.

Paton, B., Hohwy, J., \& Enticott, P. G. (2012). The rubber hand illusion reveals proprioceptive and sensorimotor differences in autism spectrum disorders. Journal of autism and developmental disorders, 42(9), 1870-1883.

Pawełczyk, A., Kotlicka-Antczak, M., Łojek, E., Ruszpel, A., \& Pawełczyk, T. (2018). Schizophrenia patients have higher-order language and extralinguistic impairments. Schizophrenia research, 192, 274-280.

Peled, A., Pressman, A., Geva, A. B., \& Modai, I. (2003). Somatosensory evoked potentials during a rubber-hand illusion in schizophrenia. Schizophrenia research, 64(2-3), 157163.

Progovac L, Benítez-Burraco A (2019) From physical aggression to verbal behavior: language evolution and self-domestication feedback loop. Frontiers in Psychology, 10:2807. https ://doi.org/10.3389/fpsyg.2019.02807 
Quoidbach, J., Hansenne, M., \& Mottet, C. (2008). Personality and mental time travel: A differential approach to autonoetic consciousness. Consciousness and Cognition, 17(4), 1082-1092.

Rapp, A. M., Felsenheimer, A. K., Langohr, K., \& Klupp, M. (2018). The comprehension of familiar and novel metaphoric meanings in schizophrenia: A pilot study. Frontiers in psychology, 8, 2251.

Race, E., Keane, M. M., \& Verfaellie, M. (2015). Sharing mental simulations and stories: Hippocampal contributions to discourse integration. Cortex, 63, 271-281.

Radvansky, G. A., \& Zacks, J. M. (2014). Event cognition. New York: Oxford University Press.

Raffard, S., Esposito, F., Boulenger, J. P., \& Van der Linden, M. (2013). Impaired ability to imagine future pleasant events is associated with apathy in schizophrenia. Psychiatry research, 209(3), 393-400.

Ramachandran, V. S., \& Hubbard, E. M. (2001). Synaesthesia--a window into perception, thought and language. Journal of consciousness studies, 8(12), 3-34.

Renes, R. A., Vermeulen, L., Kahn, R. S., Aarts, H., \& van Haren, N. E. (2013). Abnormalities in the establishment of feeling of self-agency in schizophrenia. Schizophrenia Research, 143(1), 50-54.

Riches, N. G., Loucas, T., Baird, G., Charman, T., \& Simonoff, E. (2012). Interpretation of compound nouns by adolescents with specific language impairment and autism spectrum disorders: An investigation of phenotypic overlap. International journal of speech-language pathology, 14(4), 307-317.

Rochester S, Martin JR. (1979) Crazy talk: a study of the discourse of schizophrenic speakers. New York: Plenum. 
Rothen, N., \& Meier, B. (2013). Why vicarious experience is not an instance of synesthesia. Frontiers in Human Neuroscience, 7, 128.

Rouw, R., Scholte, H. S., \& Colizoli, O. (2011). Brain areas involved in synaesthesia: a review. Journal of neuropsychology, 5(2), 214-242.

Roy, P. \& Chiat, S. (2013) Teasing apart disadvantage from disorder: the case of poor language. in Current Issues in Developmental Disorders (ed. Marshall, C. R.) 125-150 (Psychology Press, 2013).

Russell, J. (1996). Agency: Its role in mental development. Hove UK Erlbaum: Taylor \& Francis.

Russell, J., and Hill, E. L. (2001). Action-monitoring and intention reporting in children with autism. J. Child Psychol. Psychiatry 42, 317-328.

Russell, J., and Jarrold, C. (1999). Memory for actions in children with autism: self versus other. Cogn. Neuropsychiatry 4, 303-331

Santiesteban I, Bird G, Tew O, Cioffi MC, Banissy MJ.(2015) Mirror-touch synaesthesia: difficulties inhibiting the other. Cortex 71, 116-121. (doi:10.1016/j.cortex.2015.06.019)

Schechtman, M. (1996). The constitution of selves. Ithaca, NY: Cornell University Press.

Sah, W. H., \& Torng, P. C. (2015). Narrative coherence of Mandarin-speaking children with high-functioning autism spectrum disorder: An investigation into causal relations. First Language, 35(3), 189-212.

Shield, A., Meier, R. P., \& Tager-Flusberg, H. (2015). The use of sign language pronouns by native-signing children with autism. Journal of autism and developmental disorders, 45(7), 2128-2145. 
Silbersweig, D. A., Stern, E., Frith, C., Cahill, C., Holmes, A., Grootoonk, S., ... \& Frackowiak, R. S. J. (1995). A functional neuroanatomy of hallucinations in schizophrenia. Nature, 378(6553), 176-179.

Sinha, C., \& Gärdenfors, P. (2014). Time, space, and events in language and cognition: a comparative view. Ann. NY Acad. Sci, 1326, 72-81.

Smith, A. D. M. and Höfler, S. (2014). The pivotal role of metaphor in the evolution of human language. In J. E. Díaz-Vera (ed.), Metaphor and Metonomy across Time and Cultures: Perspectives on the Sociohistorical Linguistics of Figurative Language, 123-140. Amsterdam: De Gruyter.

Sowden, S., \& Shah, P. (2014). Self-other control: a candidate mechanism for social cognitive function. Frontiers in human neuroscience, 8, 789.

Speer, N. K., Zacks, J. M., \& Reynolds, J. R. (2007). Human brain activity time-locked to narrative event boundaries. Psychological Science, 18(5), 449-455.

Spelke, E. S. (2000). Core knowledge. American psychologist, 55(11), 1233.

Spelke, E. (2003). What makes us smart? In D. Gentner and S. Goldin-Meadow (eds.), Language in Mind, 277-311. Cambridge, MA: MIT Press.

Stefanatos, G. A., \& Baron, I. S. (2011). The ontogenesis of language impairment in autism: a neuropsychological perspective. Neuropsychology Review, 21(3), 252-270.

Stephane, M., Kuskowski, M., McClannahan, K., Surerus, C., \& Nelson, K. (2010). Evaluation of speech misattribution bias in schizophrenia. Psychological medicine, 40(5), 741-748.

Stephane, M., Kuskowski, M., \& Gundel, J. (2014). Abnormal dynamics of language in schizophrenia. Psychiatry research, 216(3), 320-324.

Stern, D. N. (1985). The interpersonal world of the infant. New York: Basic

Sterponi L., de Kirby K., Shankey J. (2015) Subjectivity in Autistic Language: Insights on Pronoun Atypicalityfrom Three Case Studies. In: O’Reilly M., Lester J.N. (eds) The 
Palgrave Handbook of Child Mental Health.Palgrave Macmillan, London. https://doi.org/10.1057/9781137428318_15

Sterzer, P., Adams, R. A., Fletcher, P., Frith, C., Lawrie, S. M., Muckli, L., ... \& Corlett, P. R. (2018). The predictive coding account of psychosis. Biological psychiatry, 84(9), 634643.

Stirling L, Douglas S, Leekam S, Carey L (2014) The use of narrative in studying communication in autism spectrum disorders. In: Arciuli J, Brock J (eds) Communication in autism. John Benjamins, Amsterdam, pp 169-216

Surguladze, S., Rossell, S., Rabe-Hesketh, S., \& David, A. S. (2002). Cross-modal semantic priming in schizophrenia. Journal of the International Neuropsychological Society, 8(7), 884-892.

Tager-Flusberg, H., Paul, P., \& Lord, C. (2005). Language and communication in autism. In F. R. Volkmar, A. Klin, R. Paul, \& D. J. Cohen (Eds.), Handbook of autism and pervasive developmental disorders (3rd ed., pp. 335-364). Hoboken, NJ: Wiley.

Tang, S. X., Kriz, R., Cho, S., Park, S. J., Harowitz, J., Gur, R. E., ... \& Liberman, M. Y. (2021). Natural language processing methods are sensitive to sub-clinical linguistic differences in schizophrenia spectrum disorders. npj Schizophrenia, 7(1), 1-8.

Thakkar, K. N., Nichols, H. S., McIntosh, L. G., \& Park, S. (2011). Disturbances in body ownership in schizophrenia: evidence from the rubber hand illusion and case study of a spontaneous out-of-body experience. PloS one, 6(10), e27089.

Thomas, J., \& Kirby, S. (2018). Self domestication and the evolution of language. Biology \& philosophy, 33(1), 1-30.

Thomas MS, Davis R, Karmiloff-Smith A, Knowland VC, Charman T. The over-pruning hypothesis of autism. Dev Sci. 2016 Mar;19(2):284-305. doi: 10.1111/desc.12303. Epub 2015 Apr 6. PMID: 25845529. 
Tordjman, S., Celume, M. P., Denis, L., Motillon, T., \& Keromnes, G. (2019). Reframing schizophrenia and autism as bodily self-consciousness disorders leading to a deficit of theory of mind and empathy with social communication impairments. Neuroscience \& Biobehavioral Reviews, 103, 401-413.

Trabasso, T., \& Sperry, L. L. (1985). Causal relatedness and importance of story events. Journal of Memory and language, 24(5), 595-611.

Tsakiris, M., Hesse, M. D., Boy, C., Haggard, P., \& Fink, G. R. (2007). Neural signatures of body ownership: a sensory network for bodily self-consciousness. Cerebral cortex, 17(10), 2235-2244.

Uddin, L. Q., Iacoboni, M., Lange, C., \& Keenan, J. P. (2007). The self and social cognition: the role of cortical midline structures and mirror neurons. Trends in cognitive sciences, 11(4), 153-157.

Van Leeuwen, T. M., Van Petersen, E., Burghoorn, F., Dingemanse, M., \& Van Lier, R. (2019). Autistic traits in synaesthesia: Atypical sensory sensitivity and enhanced perception of details. Philosophical Transactions of the Royal Society B, 374(1787), 20190024.

van Leeuwen, T. M., Neufeld, J., Hughes, J., \& Ward, J. (2020). Synaesthesia and autism: Different developmental outcomes from overlapping mechanisms?. Cognitive Neuropsychology, 37(7-8), 433-449.

van Os J, Kapur S (2009). Schizophrenia. Lancet 374, 635-645.

Vinogradova OS (2001) Hippocampus as comparator: role of the two input and two output systems of the hippocampus in selection and registration of information. Hippocampus 11(5):578-598

Yang, Z. Y., Xie, D. J., Zou, Y. M., Wang, Y., Li, Y., Shi, H. S., ... \& Chan, R. C. (2018). Prospection deficits in schizophrenia: Evidence from clinical and subclinical samples. Journal of abnormal psychology, 127(7), 710. 
Ward, J. (2013). Synesthesia. Annual review of psychology, 64, 49-75.

Ward, J., Hoadley, C., Hughes, J. E., Smith, P., Allison, C., Baron-Cohen, S., \& Simner, J. (2017). Atypical sensory sensitivity as a shared feature between synaesthesia and autism. Scientific Reports, 7(1), 1-9.

Watanabe, T., \& Rees, G. (2016). Anatomical imbalance between cortical networks in autism. Scientific reports, 6(1), 1-10.

Williams, D., and Happé, F. (2009). Pre-conceptual aspects of self-awareness in autism spectrum disorder: the case of action-monitoring. J. Autism Dev. Disord. 39, 251-259

Willits, J. A., Rubin, T., Jones, M. N., Minor, K. S., \& Lysaker, P. H. (2018). Evidence of disturbances of deep levels of semantic cohesion within personal narratives in schizophrenia. Schizophrenia Research, 197, 365-369.

Woo TU. Neurobiology of schizophrenia onset. Curr Top Behav Neurosci. 2014;16:267-95. doi: 10.1007/7854_2013_243. PMID: 23975845; PMCID: PMC4447495.

Zacks, J. M., Speer, N. K., \& Reynolds, J. R. (2009). Segmentation in reading and film comprehension. Journal of Experimental Psychology: General, 138(2), 307.

Zahavi, D. (2010). Minimal Self and Narrative Self. A Distinction in Need of Refinement. In T. Fuchs, H. Sattel, and P. Heningsen (eds.), The Embodied Self. Dimensions, Coherence and Disorders. Stuttgart: Schattauer (3-11).

Zahavi, D. (2014). Self and Other: Exploring Subjectivity, Empathy, and Shame. Oxford: Oxford University Press

Zalla, T., Verlut, I., Franck, N., Puzenat, D., \& Sirigu, A. (2004). Perception of dynamic action in patients with schizophrenia. Psychiatry research, 128(1), 39-51.

Zalla, T., Bouchilloux, N., Labruyere, N., Georgieff, N., Bougerol, T., \& Franck, N. (2006). Impairment in event sequencing in disorganised and non-disorganised patients with schizophrenia. Brain research bulletin, 68(4), 195-202. 
Zhou, Y., Shu, N., Liu, Y., Song, M., Hao, Y., Liu, H., ... \& Jiang, T. (2008). Altered restingstate functional connectivity and anatomical connectivity of hippocampus in schizophrenia. Schizophrenia research, 100(1-3), 120-132. 